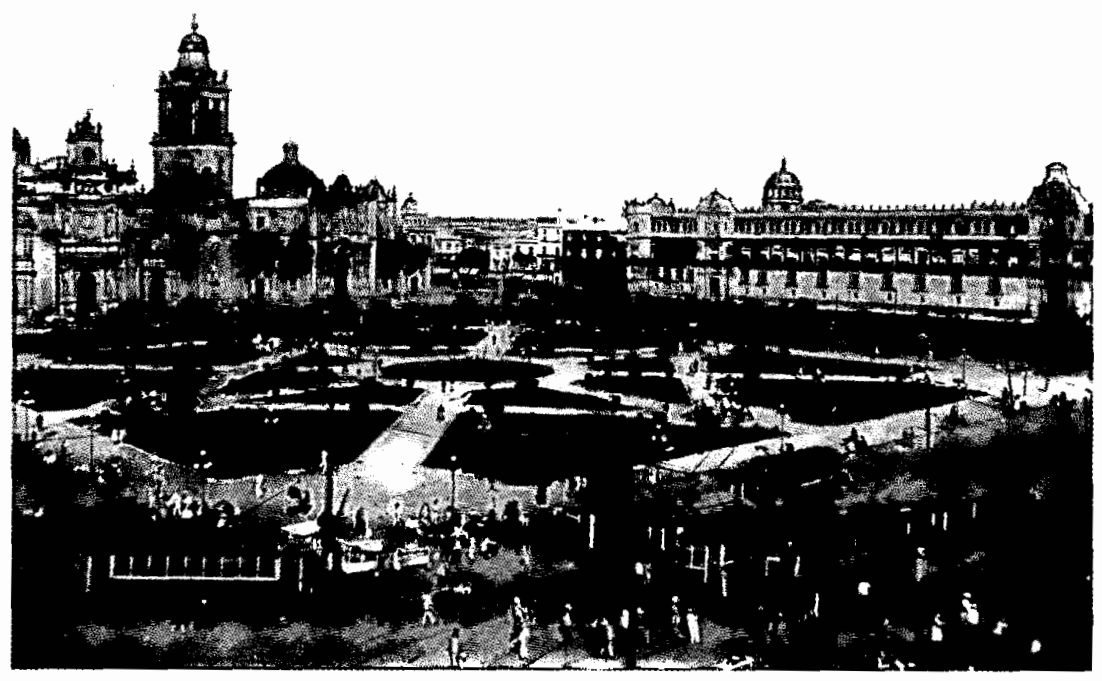




\section{Juan Manuel Ortega Riquelme}

Doctor en Ciencia Política por la Boston University. Licenciatura en Sociología Política por la Universidad Autónoma Metropolitana-Azcapotzalco. Investigador asociado C tiempo completo, interino, en el Instituto de Investigaciones Sociales-UNAM. Coordinador académico de la maestría en Sociología Política en el Instituto de Investigaciones Dr. José María Luis Mora. Candidato a investigador nacional del Sistema Nacional de Investigadores.

\section{Resumen}

Este artículo tiene como objerivo analizar el desarrollo del National Industrial Recovery Act (1933-1935) como una iniciativa del presidente de Estados Unidos F. D. Roosevelt para fundar un arreglo político de corte tripartita entre gobierno, empresarios y trabajadores; $y$ hacer frente a la crisis económica de los años treinta en Estados Unidos. El trabajo analiza el impacto que factores como el desarrollo del aparato administrativo estadunidense, el papel de la política electoral y las ideas económicas, el poder de los empresarios y la organización de los trabajadores ruvieron frente al fracaso de los objetivos del NIRA y la declaración de inconstitucionalidad por la Suprema Corte de Justicia de lo que fue el intento de política pública más ambicioso del New Deal.

Palabras clave:

Estados Unidos, New Deal, corporativismo, desarrollo institucional.

\section{Abstract}

The aim of this article is to analyze the development of the National Industrial Recovery Act (1933-1935) as an attempt by president F. D. Roosevelt to forge a tripartite political arrangement between government, businessmen and workers to cope with the economic crisis of the 1930 s in the United States. The article examines the impact that factors such as: the development of the North American administrative apparatus, the role of electoral policy and economic ideas, the power of businessmen and the organization of workers had on the failure of the NIRA's objectives and the Supreme Court of Justice's declaration of the unconstitutional nature of the most ambitious attempt at public policy of the New Deal.

\section{Key words:}

United States, New Deal, corporatism, institutional development.

Fecha de recepción:

noviembre de 2002

Fecha de aceptación: junio de 2003 


\title{
Corporativismo vs. liberalismo en los Estados Unidos del New Deal: el National Industrial Recovery Act*
}

\author{
Juan Manuel Ortega Riquelme
}

Fe en América, fe en nuestra tradición de responsabilidad personal, fe en nuestras instituciones, fe en nosotros, demanda que reconozcamos los nuevos términos del viejo contrato social. ${ }^{\mathrm{L}}$

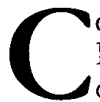

on estas palabras, Franklin D. Roosevelt expresó la urgente necesidad de confrontar los tiempos de crisis mediante la transformación de las relaciones Estado-sociedad en los Estados Unidos de la Gran Depresión. La tremenda caída de la economía, que había comenzado con el desplome del mercado de valores en Wall Street en octubre de 1929, tocaba su punto climático en 1932. Miles de industrias cerraban sus puertas, los desempleados se contaban por millones y los recortes al salario de los trabajadores eran cosa de todos los días.

Frente a la ruina económica, las promesas de campaña del candidato del Partido Demócrata a la presidencia, Franklin D. Roosevelt, se habían convertido en la única esperanza para millones de estadu-

\footnotetext{
* Agradezco los comentarios de Gabriela Barajas y de los tres dictaminadores anónimos. Las limitaciones del trabajo son, desde luego, únicamente mías.

${ }^{1}$ Franklin D. Roosevelt, discurso de campaña en Commonwealth Club, San Francisco, 23 de septiembre de 1932. Tomado de Zinn, New, 1966, p. 52.
}

nidenses. En sus discursos, éste criticaba el egoísmo de los intereses individuales. La Gran Depresión era el resultado de la superabundancia, de la falta de planeación y de una injusta distribución de la riqueza. Para el candidato, una nueva filosofía de la planeación y de la cooperación entre los diferentes grupos de la sociedad era el artificio para escapar del caos económico; en sus propias palabras:

Tratemos de no confundir objetivos de métodos. La gran mayoría de los supuestos líderes de la nación no pueden ver el bosque debido a los árboles. La gran mayoría de ellos no pueden reconocer la necesidad vital de planear para definir objetivos. El verdadero liderazgo es el que llama a la definición de objetivos y busca el apoyo de la opinión pública para lograr esos objetivos. ${ }^{2}$

En las elecciones presidenciales de 1932, Roosevelt salió victorioso frente a su adversario republicano, el presidente Herbert Hoover (1929-1933). Inmediatamente después de presentar su juramento como presidente número 32 de Estados Unidos, el 4 de marzo de 1933 , el nuevo presidente tomó las riendas del

${ }^{2}$ Discurso en la Oglethorpe University en Atlanta, Georgia, el 22 de mayo de 1932, en ibid., p. 83. 
país para modificar de manera importante la organización de las relaciones políticas, económicas y sociales en lo que se ha denominado como el New Deal.

Durante los "primeros 100 días" $^{3}$ de su administración, Roosevelt solicitó el apoyo del Congreso a un abanico de propuestas de legislación para la creación de fondos asistenciales para el bienestar de la población pobre y desempleada, así como de apoyos a la industria y a la agricultura. ${ }^{4}$ Durante lo que algunos han denominado como el primer New Deal (19321935), el presidente Roosevelt obtuvo el apoyo del Congreso a un número importante de propuestas de legislación que se tradujeron en leyes: el Agricultural Adjustment Act, el Banking Act, el Securities Act, el Tennesse Valley Act y el National Industrial Recovery Act, las cuales, a su vez, crearon una avalancha de nuevos organismo federales como la Tennesse Valley Authority, el Federal Emergency Relief, la Agricultural Adjustment Administration, los Civilian Conservation Corps, la Public Works Administration y la National Recovery Administration. ${ }^{5}$

${ }^{3}$ Curiosamente es a partir del gobierno de Franklin D. Roosevelt que los analistas estadunidenses comienzan a evaluar los primetos 100 días del gobierno de cada periodo presidencial. Como todos sabemos, este tipo de evaluación es ya una práctica generalizada en muchas naciones democráticas de occidente.

${ }^{4}$ Morison, Oxford, 1965.

${ }^{5}$ Para muchos el segundo New Deal comienza en 1935, bajo el marco de una nueva avalancha de organismos federales y leyes, entre ellos el Wagner Labor Relations Board, la Rural Electrification Administration, la Works Progress Administration, la Fram Security Administration, la Soil Conservation and Domestic Allotment Act, el Public Utilities Holding Company Act y el Social Security Act, entre otras.
La nueva filosofía de planeación y cooperación propuesta por el presidente y su equipo tomó forma en el National Industrial Recovery Act (NIRA) de 1933, el cual sería definido por el mismo Roosevelt como "la pieza de legislación más importante y extensa jamás legislada por el Congreso estadunidense". ${ }^{6}$ Esta ley fue un mecanismo dirigido a la planeación para la recuperación industrial por medio de la cooperación entre empresarios, trabajadores y gobierno. Este intento de arreglo político ha sido considerado por diversos analistas como un singular intento de Roosevelt por generar un sistema de negociación de tipo corporativista, es decir, de negociación tripartita entre un número limitado de organizaciones empresariales, obreras y de gobierno para regular las relaciones económicas entre los actores. ${ }^{7} \mathrm{Sin}$ embargo, una característica del NIRA fue su fracaso al ser declarado anticonstitucional por la Suprema Corte de Justicia de Estados Unidos en mayo de 1935.

El propósito del presente artículo es el de evaluar la noción del "excepcionalismo estadunidense" y conocer el curso de eventos que llevaron a una nación caracterizada por su profundo liberalismo político y económico al diseño de un arreglo político tripartita de controles sobre la economía, al igual que ocurría en otras naciones europeas y latinoamericanas. ¿De qué forma la crisis económica de los años treinta empujó la organización de la economía y la política de Estados Unidos hacia un cambio radical? y ¿cuál fue el papel de los arreglos institucionales establecidos en la vida de este experimento político?, son algunas de las preguntas

\footnotetext{
${ }^{6}$ Hawley, New, 1966, p. 19.

7 Skocpol y Finegold, "State", 1982, pp. 255-278.
} 
que se tratan de responder a lo largo de este artículo.

El origen y fin del NIRA están intrínsecamente relacionados con cuatro factores que serán analizados a continuación: el desarrollo del aparato administrativo estadunidense, el papel de la política y las ideas en la crisis del 29, la fuerza de los empresarios en el diseño de política pública y la debilidad de la organización obrera en Estados Unidos.

\section{¿QUÉ FUE EL NATIONAL INDUSTRIAL RECOVERY ACT?}

La Gran Depresión fue una "coyuntura crítica" en la historia de Estados Unidos en tanto que indujo a un profundo debate sobre la organización de su economía y su política. ${ }^{8} \mathrm{La}$ respuesta institucional ante la crisis del 29 es mejor conocida como el New Deal.

Para el presidente Roosevelt, las causas fundamentales de la Gran Depresión fueron la falta de planeación; la sobreproducción, resultado de la intensa competencia entre empresas, y los bajos ingresos de los estadunidenses. La respuesta a dichos problemas se encontraba en la planeación mediante la coordinación de los sectores productivos. Durante los primeros años del New Deal, la situación económica eran tan desesperada que para muchos las "fuerzas" del mercado no encontrarían el equilibrio y, por lo tanto, era necesario lograr la "coordinación, [el] orden, [la] estabilización, [y la] distribución del mercado y de la administración"? 1998.

${ }^{8}$ Gourevitch, Politics, 1986; Rodgers, Atlantic,

${ }^{9}$ Gourevitch, Politics, 1986, p. 149.
El NIRA fue creado con el objetivo de coordinar los intereses del gobierno, de empresarios y de trabajadores para poder así planear y regular la competencia por los mercados. El nacimiento de esta ley fue un proceso relativamente rápido y producto de distintos intentos por generar un programa para la estabilización de la economía. Ésta fue un derivado de los proyectos del poder legislativo estadunidense por estabilizar las relaciones industriales durante la Gran Depresión, en particular, de una propuesta de ley introducida al Congreso por el senador demócrata Hugo L. Black, de Alabama. ${ }^{10}$ Dicha propuesta de ley, conocida como Black's Thirty Hour Bill, pretendía regular las relaciones comerciales y laborales entre los estados de la federación al incorporar las demandas de los trabajadores organizados en la American Federation of Labor. La legislación llamaba a la prohibición del comercio interestatal de bienes producidos por trabajadores con jornadas laborales de más de seis horas diarias o de más de cinco días a la semana. ${ }^{11}$ La propuesta del senador Black fue votada y aceptada dentro del Senado por 53 votos a favor y 30 en contra; sin embargo, fue congelada en la Cámara de Representantes como resultado del cabildeo del presidente Roosevelt en contra de la propuesta. El presidente juzgó que el planteamiento dejaba de lado el asunto del salario mínimo, además de que la propuesta de una semana laboral de 30 horas era una solución extrema,

\footnotetext{
${ }^{10} \mathrm{El}$ senador Black fue nombrado miembro de la Suprema Corte de Justicia de Estados Unidos en 1937 por el presidente Roosevelt. En línea internet <http://bioguide.congress.gov/scripts/biodisplay.pl? index $=$ B000499> .

I' Levine, Class, 1988, pp. 70-71.
} 


\section{SECUENCIA}

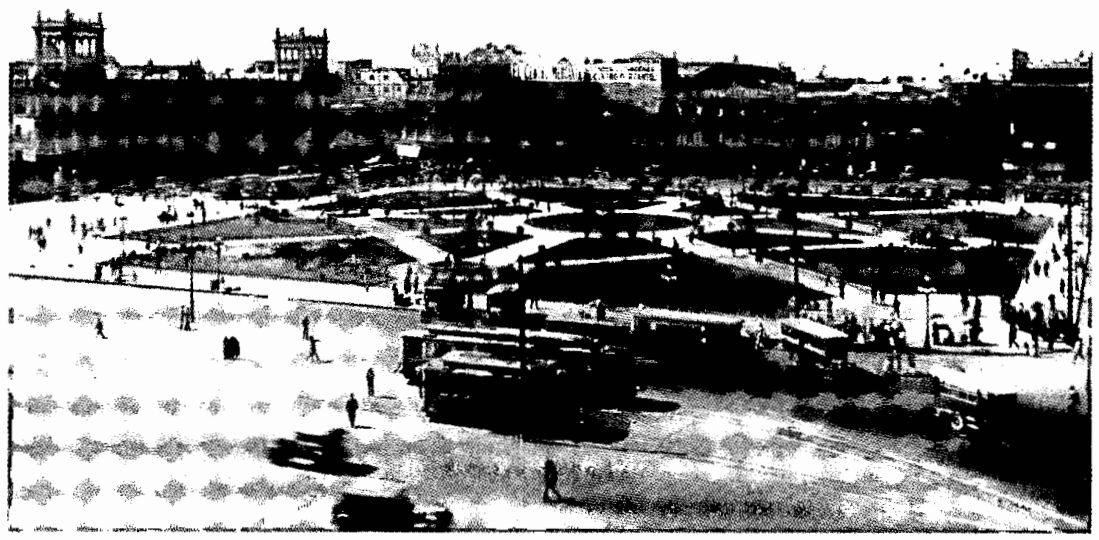


poco flexible y anticonstitucional que debía ser rechazada por el Congreso. ${ }^{12}$

Para poder hacer a un lado el Thirty Hour Bill, y canalizar las presiones que buscaban definir una estrategia de recuperación económica, Roosevelt designó a Frances Perkins, de la Secretaría del Trabajo, para desarrollar una alternativa a la propuesta de Black. El 17 de abril del mismo año, Perkins propuso al Comité de Asuntos Laborales de la Cámara de Representantes una serie de enmiendas a la propuesta de Black. En su proposición Perkins llamaba al establecimiento de un salario mínimo basado en la recomendación de consejos industriales en donde industriales, gobierno y trabajadores tendrían representantes. Además de la propuesta de salario mínimo, la Secretaría del Trabajo aceptaba, de forma limitada y con excepciones, la semana laboral de 30 horas, así como límites al uso de maquinaria por los trabajadores. ${ }^{13}$ La propuesta fue duramente criticada por los líderes empresariales, la Chamber of Commerce, la National Association of Manufactures y la American Bar Association por considerar que generaría más desempleo, además de ser inflexible y poco práctica. ${ }^{14}$

Al mismo tiempo que Perkins diseñaba su propuesta, Raymond Moley, subsecretario de Estado y parte del Brain Trust, ${ }^{15}$ junto con el general Hugh $\mathrm{S}$.

\footnotetext{
${ }^{12}$ Hawley, New, 1966, p. 22. La propuesta de regulación sobre la semana laboral fue recuperada en 1938 cuando se estableció el Fair Labor Standards Act; sin embargo, la semana de trabajo se definió no en 30 , sino en 40 horas semanales. Véase en internet <http://www.timesizing.com/2blkbill.htm>.

${ }^{13}$ Hawley, New, 1966, p. 22.

${ }^{14}$ Ibid, pp. 22-23.

${ }^{15}$ El Brain Trust es conocido como el grupo de académicos provenientes de la Columbia University
}

Johnson, un militar con gran experiencia en la War Industries Board, y con el apoyo de hombres de negocios como Bernard Baruch y Alexander Sachs redactaban una propuesta de legislación para la recuperación industrial. ${ }^{16}$ Por su parte el senador Robert F. Wagner, demócrata de Nueva York, junto con Meyer Jacobstein, un viejo político del estado de Nueva York, y la asesoría de Harold Moulton de la Brookings Institution también diseñaban su propia propuesta que combinaba programas de obra pública junto con mecanismos de planificación industrial mediante las organizaciones empresariales. ${ }^{17}$

A inicios de mayo de 1933, Wagner y Johnson presentaron sus recomendaciones al presidente. Sin embargo, éste las encontró poco adecuadas. Roosevelt volvió a designar un nuevo comité que conjuntaba los esfuerzos de todas las propuestas para lograr así una propuesta de recuperación satisfactoria. El nuevo comité estaba conformado por Wagner y Johnson, pero también por Donald R. Richberg, un reconocido abogado laboral asociado con los sindicalistas ferroviarios; John Dickinson, subsecretario de Comercio; Frances Perkins, secretario del Trabajo, y Lewis Douglas, director de la Oficina del Presupuesto. ${ }^{18}$

Por su parte, la National Association of Manufacturers exigió mayor presencia de los empresarios en el comité bajo la amenaza de oponerse a cualquier medida de recuperación industrial si no eran con-

que asesoraron al presidente Roosevelt a lo largo de su presidencia.

${ }^{16}$ Hawley, New, 1966, p. 23; Levine, Class, 1988 , pp. $70-71$.

${ }_{17}$ Hawley, New, 1966, pp. 23-25.

${ }^{18}$ Levine, Class, 1988, pp. 71-74. 
sultados. El presidente aceptó y designó a los representantes empresariales de la Chamber of Commerce, la National Association of Manufacturers, así como también a distintos líderes empresariales como Lammont Du Pont para que se integraran al equipo de redacción de la nueva propuesta de recuperación industrial. El 13 de mayo de 1933 todas las partes llegaron a un acuerdo y la propuesta de legislación conocida como el NIRA fue enviada al Congreso el 17 de mayo. ${ }^{19}$

Esta ley buscaba crear un clima de cooperación entre el gobierno, los empresarios y los trabajadores para encontrar el camino hacia la recuperación industrial. Proponía: 1) la creación de un sistema de códigos legales que aseguraran la competencia justa entre empresas al controlar precios y producción industrial. Sin duda alguna el NIRA se enfrentaba a las leyes antimonopolio (antitrust laws) en tanto que éstas impedían una mejor coordinación sobre los precios y la producción industrial; 2) el establecimiento de un salario mínimo, así como de un tope máximo a la jornada laboral; 3) el derecho de los trabajadores a organizarse y negociar de forma colectiva mediante sus representantes obreros y sin intervención de los patrones, y 4) el establecimiento de un programa directo de apoyo al empleo que más tarde tomó forma en la Public Works Administration. ${ }^{20}$

19 Ibid.

${ }^{20}$ National Recovery Administration (en adelante NRA), Handbook, 1933. El NIRA estaba constituido por tres partes o títulos, dos de los cuales tenían que ver con la obra pública y los impuestos para financiarla, el título I, el más conocido, tenía que ver con la formulación de códigos industriales. En la sección 3 del título I se planteaba la capacidad del pre-
El título I, sección 1 del NIRA describe claramente la disposición hacia la cooperación del gobierno de Roosevelt:

Por la presente se declara que la política del Congreso será remover los obstáculos al libre tránsito del comercio interestatal y exterior que limitan el valor del mismo; y servir al bienestar común mediante la promoción de la organización de la industria con el propósito de generar una acción cooperativa entre grupos comerciales, inducir y mantener una acción unida entre obreros y administradores bajo la adecuada supervisión y sanción del gobierno, eliminar prácticas competitivas injustas, promover a su máximo la capacidad productiva presente de las industrias, evitar excesivas restricciones en la producción (excepto cuando sean requeridas temporalmente), incrementar el consumo de productos agrícolas e industriales mediante el aumento del poder de compra, reducir y aliviar el desempleo, mejorar los estándares laborales y, en otro respecto, rehabilitar la industria y conservar los recursos naturales. ${ }^{21}$

sidente para establecer códigos industriales y de comercio, siempre y cuando fueran equitativos, representativos y no promovieran el desarrollo de monopolios y sus prácticas. La sección 7 del título I tenía que ver con la reglamentación sobre el salario mínimo, las jornadas laborales y las condiciones de trabajo. Se añadió la sección 7(a), la cual declaraba el derecho de los trabajadores a organizarse y elegir a sus representantes para negociar en forma colectiva. $\mathrm{La}$ sección 5 exentaba a los códigos industriales de las teyes antimonopolio. Hawley, New, 1966, pp. 31-33.

21 "It is hereby declared to be the policy of Congress to remove obstructions to free flow of interstate and foreign commerce which tend to diminish the amount thereof; and to provide for the general welfare by promoting the organization of industry for the purpose of cooperative action among trade groups, to induce and maintain united action of labor 
Esta ley otorgó al presidente el poder de aprobar y prescribir los códigos de "competencia justa" y de evaluar las prácticas laborales en las distintas industrias. De igual manera, ésta otorgó a las cortes distritales, a los abogados de distrito (district attorneys) y al abogado de la nación (attorney general) el poder de prevenir y de restringir las violaciones a cualquiera de los códigos legales establecidos por el NIRA. ${ }^{22}$

Para establecer, desarrollar y administrar las prerrogativas de política comercial, industrial y laboral dispuestas por los códigos del NIRA, se creó la National Recovery Administration (NRA). La organización de ésta estaba conformada por secciones y oficiales administrativos, así como por tres comités asesores: el industrial, el laboral y el de consumidores. ${ }^{23}$ Este organismo se estableció como una agencia independiente del gobierno de Estados Unidos sólo responsable ante el ejecutivo. ${ }^{24}$ El NIRA no sólo daba vida a la NRA, también a la Public Works Administration, encabezada por el secretario del Interior, Harold L. Ickes. ${ }^{25}$

Durante los debates en el Congreso para convertir la propuesta de legislación

and management under adequate governmental sanctions and supervision, to eliminate unfair competitive practices, to promote the fullest possible utilization of the present productive capacity of industries, to avoid undue restriction of production (except as may be temporally required), to increase the consumption of industrial and agricultural products by increasing purchasing power, to reduce and relieve unemployment, to improve standards of labor, and otherwise to rehabilitate industry and to conserve natural resources." NRA, Handbook, 1933, p. 4.

${ }^{22}$ Ibid., p. 6.

${ }^{23}$ Ibid., p. 44.

${ }^{24}$ Skocpol y Finegold, "State", 1982, p. 263.

${ }^{25}$ Badger, New, 1989, p. 81. en ley, la gran mayoría de la oposición surgió de los antitrusters y pequeños empresarias preocupados por la posibilidad de que el NIRA generara prácticas monopólicas y alentara la sindicalización de los trabajadores. Sin embargo, el control demócrata sobre la cámara baja del Congreso, resultado del landslide electoral del Partido Demócrata en las elecciones de 1932, dio la posibilidad de que la propuesta de legislación fuera votada a favor sin mayor problema. El 26 de mayo de 1933 la Cámara de Representantes del Congreso de Estados Unidos aprobó la medida con 325 votos a favor y 76 en contra. ${ }^{26}$

En el Senado las cosas fueron menos fáciles. Hubo importantes intentos para eliminar los casi 500 códigos de "competencia legítima" que controlaban $96 \%$ de la industria estadunidense, ${ }^{27}$ suprimir los derechos de los trabajadores a la negociación colectiva y añadir un impuesto a la venta de productos manufacturados. Pero la oposición al control sobre precios y producción, al debilitamiento de las regulaciones antimonopólicas o la defensa a la negociación colectiva, descritas en la sección 7(a) del NIRA, no fueron un obstáculo para cambiar la mente de los llamados nuevos "demócratas urbanos-liberales", quienes habían logrado conquistar el control del Senado en las elecciones de $1932 .^{28}$ El Senado votó la legislación con 59 votos a favor y 37 en contra. El 16 de junio de 1933, el presidente Roosevelt firmó el National Industrial Recovery Act. ${ }^{29}$

Si bien esta ley era una gran pieza de política industrial y laboral, ésta era con-

\footnotetext{
${ }^{26}$ Levine, Class, 1988, pp. 74-75.

${ }^{27}$ Skocpol y Finegold, "State", 1982, p. 205.

${ }^{28}$ Levine, Class, 1988, p. 77.

${ }^{29}$ McQuaid, Big, 1982, p. 26.
} 
siderada sólo una medida de recuperación con un plazo de vida limitado, se estableció entonces que el acuerdo:

llegaría a su término al fin de dos años, después del día de su promulgación o antes si el presidente o el Congreso en resolución conjunta declararan que la emergencia reconocida bajo la sección 1 había terminado. ${ }^{30}$

Dos años después de su establecimiento, en 1935, la administración de Roosevelt concibió la posibilidad de prolongar la vida del NIRA; sin embargo, antes de que la Cámara de Representantes y el Senado llegaran a alguna conclusión, la Suprema Corte de Justicia de Estados Unidos sancionó en contra de ésta y la declaró una medida anticonstitucional. La decisión tomada por la Suprema Corre fue conocida como la Schecter Decision. ${ }^{31}$

La resolución de la Suprema Corte fue tomada a partir de los sucesos relacionados con la compañía kosher de aves de corral Schecter Poultry Corporation, de Brooklyn, Nueva York, la cual había sido acusada por la NRA de haber violado los códigos de salarios, de horarios, de salubridad y de prácticas comerciales de la industria avícola. En octubre de 1934, los hermanos Joseph, Martin, Alex y Aaron Schecter fueron encontrados culpables por una corte de distrito cuya decisión fue más tarde sustentada por una corte de apela-

30 "It would ceases to exist at the expiration of two years after the date of enactment of this Act, or sooner if the president shall by proclamation or the Congress shall by joint resolution declared that the emergency recognized by section 1 has ended." NRA, Handbook, 1933, p. 5.

${ }^{31}$ Gunther, Constitutional, 1985, p. 125. ciones. ${ }^{32}$ La NRA decidió llevar el caso ante la Suprema Corte de Justicia como una prueba para probar la siempre cuestionada constitucionalidad del NIRA. ${ }^{33}$ La Schecter Poultry Corporation fue apoyada en su defensa por el Iron and Steel Institute, que buscaba el fin de la intervención gubernamental en la economía. ${ }^{34}$ La defensa en contra de la NRA argumentó que:

1) el sistema de códigos significaba una delegación inconstitucional del poder del legislativo al ejecutivo, 2) que el negocio se encontraba fuera del rango del poder del ejecutivo frente al comercio, y 3) que la libertad y la propiedad estaban siendo privadas $\sin$ la existencia de un proceso legal. ${ }^{35}$

El 27 de mayo de 1935 la Suprema Corte (en voz de su chief justice Charles Evans Hughes), dio su veredicto a favor de la compañía de aves de corral y refutó las razones de la NRA. La Suprema Corte consideró que las extraordinarias condiciones que vivía el país no justificaban un incremento en los poderes constitucionales del ejecutivo, definidas por la sección tercera del NIRA, y que "los esfuerzos por la recuperación hechos por el gobierno federal deberían serlo de una manera consistente con la autoridad conferida por la constitución" ${ }^{36}$ La Suprema Corte daba el tiro de gracia a la NRA, si bien permitía la continuidad de la Public Works Administration bajo la administración de Ickes.

La sentencia en contra del NIRA establecía que el Congreso había delegado

\footnotetext{
${ }^{32}$ Hawley, New, 1966, pp. 127-128.

${ }^{33}$ Levine, Class, 1988, p. 87.

${ }^{34}$ Badger, New, 1989, p. 93.

${ }^{35}$ Levine, Class, 1988 , p. 87.

${ }^{36}$ Gunther, Constitutional, 1985, p. 125.
} 
poderes legislativos al ejecutivo sin definir los estándares y lineamientos para la discreción presidencial. Si bien el veredicto de la Suprema Corte en contra de esta ley ilustra los límites al poder ejecutivo dentro del sistema político estadunidense, la mayoría de los historiadores y analistas políticos consideran que ésta estaba agonizando mucho tiempo antes de que la Suprema Corte determinara su sentencia.

DesarRollo del aparato ADMINISTRATIVO DEL. ESTADO ESTADUNIDENSE, IDEOLOGÍA, POLÍTICA Y EL NIRA

La creación y la caída de la NRA como mecanismo para planear y regular la competencia del mercado interno deben ser analizadas mediante las particularidades propias de la construcción del Estado.

El desarrollo del aparato administrativo durante el New Deal estuvo influido por aspectos tanto institucionales como coyunturales. Es decir, institucionales en cuanto a las transformaciones del aparato público a partir de la Progressive Era de los años veinte, y coyunturales en referencia al realineamiento electoral de 1932 y los cambios radicales en la política pública y en la ideología antiburocrática como resultado de la profunda crisis económica experimentada a partir de 1929.

\section{Instituciones: el desarrollo del aparato administrativo}

La evolución del aparato administrativo público en Estados Unidos fue producto del constante incremento del papel de la burocracia en la política, así como de una bien establecida y desarrollada democracia electoral. ${ }^{37}$ Después de la guerra civil (1861-1865), las cortes y los partidos políticos emergieron triunfantes del proceso de reconstrucción al controlar las decisiones más importantes del aparato de Estado. Entre 1874 y 1896, las campañas políticas nacionales fueron sumamente competidas y los partidos se dividieron el control sobre el gobierno nacional. ${ }^{38}$ La racionalidad política estaba condicionada a los imperativos de mantener un gobierno eficiente a partir de sostener y asegurar las maquinarias políticas locales y las coaliciones nacionales para apoyar a los candidatos presidenciales. ${ }^{39}$ Los recursos del gobierno no estaban protegidos de un uso partidista y el poder político de los partidos con sus maquinarias locales impedían la creación de un poder estatal centralizado, estable y capaz de enfrentar los diversos problemas de una sociedad con una estructura social y económica cada día más compleja y en continuo cambio. Junto con los partidos políticos, las cortes desempeñaron un papel central durante el proceso de reconstrucción de la nación después de la guerra civil. Ante la pérdida de la hegemonía de los partidos y de su incapacidad para gobernar un país que dejaba la esclavitud y una economía agrícola, y se encaminaba hacia un importante proceso de industrialización, las cortes respondieron a este vacío de poder. ${ }^{40}$ Las cortes se encontraron a sí mismas como la única institución capaz de crear política pública. La política económica diseñada por el poder judicial se desarro-

\footnotetext{
${ }^{37}$ Skowronek, Building, 1982.

${ }^{38}$ Ibid., p. 39.

${ }^{39}$ Ibid.

${ }^{40}$ Ibid., p. 41
} 
llaba bajo los lineamientos del laissez-faire, que definía claramente las fronteras entre las esferas privada y pública, la acción del Estado y las regulaciones del mercado. ${ }^{41}$ En consecuencia, el proceso de desarrollo industrial capitalista estaba sujeto a las decisiones del poder judicial y de los partidos políticos. El poder de las corporaciones estaba acotado únicamente por las leyes antimonopolio plasmadas en el Sherman Antitrust Act de 1890 y la Interstate Commerce Comission. Sin embargo, si bien el Sherman Act prohibía los monopolios, como también cualquier intento de construirlos, su aplicación era laxa y su interpretación limitada, de allí que la gran expansión y la consolidación de las grandes corporaciones estadunidenses se hayan dado entre 1897 y $1904 .{ }^{42}$ De acuerdo con Steven Skowronek, los elementos distintivos del desarrollo político estadunidense eran dos: la falta de un ejército o poder burocrático centralizado y una bien organizada democracia popular. ${ }^{43}$

En los inicios de 1900, un grupo de profesionistas universitarios dentro del Partido Republicano vieron la necesidad de volver a fundar los cimientos de la política y de la economía en Estados Unidos mediante la construcción de nuevas coaliciones políticas y del control del aparato de Estado. Para este movimiento, conocido como Movimiento Progresista, la base de la nueva era industrial en Estados Unidos tenía como pieza central la reorganización del aparato nacional administrativo. ${ }^{44} \mathrm{El}$

${ }^{41} \mathrm{Ibid} ., \mathrm{p} .42$.

${ }^{42}$ Hawley, New, 1966, p. 6.

${ }^{43}$ Skowronek, Building, 1982, p. 41.

${ }^{44}$ Ibid., pp. 165-167. Véase el discurso de Elihu Root ante la New York State Bar Association en 1912, en Morison, Oxford, 1965, p. 811. ideal progresista era un gobierno prescrito por lineamientos técnico-administrativos, en donde una burocracia altamente calificada y especializada racionalizaba las decisiones del aparato de gobierno, siempre bajo el credo del libre mercado. El alineamiento electoral de 1896 fue fundamental, pues al permitir que el Partido Republicano controlara el aparato de gobierno por más de quince años (1896-1911), tanto el Congreso como el ejecutivo, se abrió una ventana de oportunidad para que los tecnócratas republicanos construyeran una coalición política interesada en el desarrollo de las capacidades administrativas del Estado en un contexto de reducidos controles constitucionales. ${ }^{45} \mathrm{El}$ proceso de modernización política del Estado llevó a la creación de un nuevo sistema institucional, que si bien estableció controles sobre el poder de la burocracia, no redefinió las nuevas responsabilidades de las nuevas $\mathrm{y}$ viejas instituciones.

Con el proceso de modernización política, las capacidades administrativas del Estado se desarrollaron en forma desigual y bajo una falta absoluta de coordinación y de control por parte del ejecutivo federal hacia el aparato administrativo. Sólo por un momento, durante la participación de Estados Unidos en la primera guerra mundial, el gobierno experimentó un crecimiento y un proceso burocrático coordinado. Los intentos por organizar a los empresarios hacia la cooperación con el gobierno no fueron una novedad del New Deal y del NIRA. Durante la primera guerra mundial, la War Industries Board (WIB), creada bajo el liderazgo del financiero Bernard Baruch, fue un artilugio

${ }^{45}$ Skowronek, Building, 1982, p. 176. 
para organizar a la comunidad empresarial en su apoyo a la guerra. Sin embargo, un rasgo distintivo de la WIB frente al NIRA de Roosevelt es que no generaba controles positivos sobre la economía, era más bien un mecanismo de coordinación con una perspectiva no de controles sino de asesoría. ${ }^{46}$

La WIB es un ejemplo de cómo durante la emergencia de la primera guerra mundial fueron creadas agencias estatales para centralizar y coordinar los esfuerzos tanto del gobierno como de trabajadores y empresarios frente a la producción industrial, precios, salarios y racionamiento. Sin embargo, al fin de la guerra, el Congreso rechazó los intentos del gobierno federal por incrementar sus capacidades administrativas y la mayoría de las oficinas de gobierno creadas para apoyar el esfuerzo de la guerra fueron rápidamente desmanteladas ante la preocupación de un excesivo crecimiento del aparato burocrático. ${ }^{47}$ Una vez más, el retiro del Estado permitió a las corporaciones buscar su expansión bajo sus propias reglas sólo limitadas por las leyes antimonopolio definidas por el Sherman Antitrust Act y la Interstate Commerce Commission. ${ }^{48}$

El gobierno de Herbert Hoover (1929-1933) generó una estrategia antiburocrática que limitó el desarrollo del aparato administrativo. El presidente Hoover tenía en mente un "Estado asociativo" basado en un esfuerzo cooperativo entre el gobierno y las cámaras de comercio. De acuerdo con los miembros del gabinete del presidente, este esfuerzo

${ }^{46}$ Conkin, New, 1975.

${ }^{47}$ Skocpol y Finegold, "State", 1982, p. 262.

${ }^{48}$ Ibid., pp. 261-262. estaría basado en la buena voluntad de las partes más que en el control y la planeación del Estado. ${ }^{49}$ Durante la Gran Depresión, Hoover apeló a la voluntad de cooperación y solidaridad de los empresarios frente a la población pobre y desempleada más que a la intervención directa del Estado mediante el diseño de políticas de bienestar y de gasto social. La veta antiburocrática de Hoover impedía una visión de planeación e intervención estatal en la vida económica del país. Hoover promovió la organización empresarial bajo la visión de la construcción de un Estado "asociativo", sin embargo, en los tiempo de crisis, Hoover no tuvo la capacidad de persuadir a las empresas a controlar sus cuotas de producción, a reducir precios y a apoyar solidariamente a los trabajadores desempleados. ${ }^{50} \mathrm{El}$ fracaso de su propuesta de estabilización del mercado bajo un criterio voluntarista y solidario y un esquema de no intervención estatal en la economía empeoró las condiciones de vida de millones de estadunidenses.

Cuando la Gran Depresión impactó la economía de Estados Unidos, el país heredaba un sistema burocrático federal débil, donde las capacidades administrativas se encontraban difícilmente coordinadas. ${ }^{51}$ El aparato administrativo había permanecido fragmentado, pequeñas burocracias modernas habían emergido; pero no del Estado sino de las grande empresas del sector privado. ${ }^{52}$

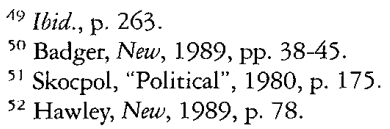




\section{SECUENCIG}

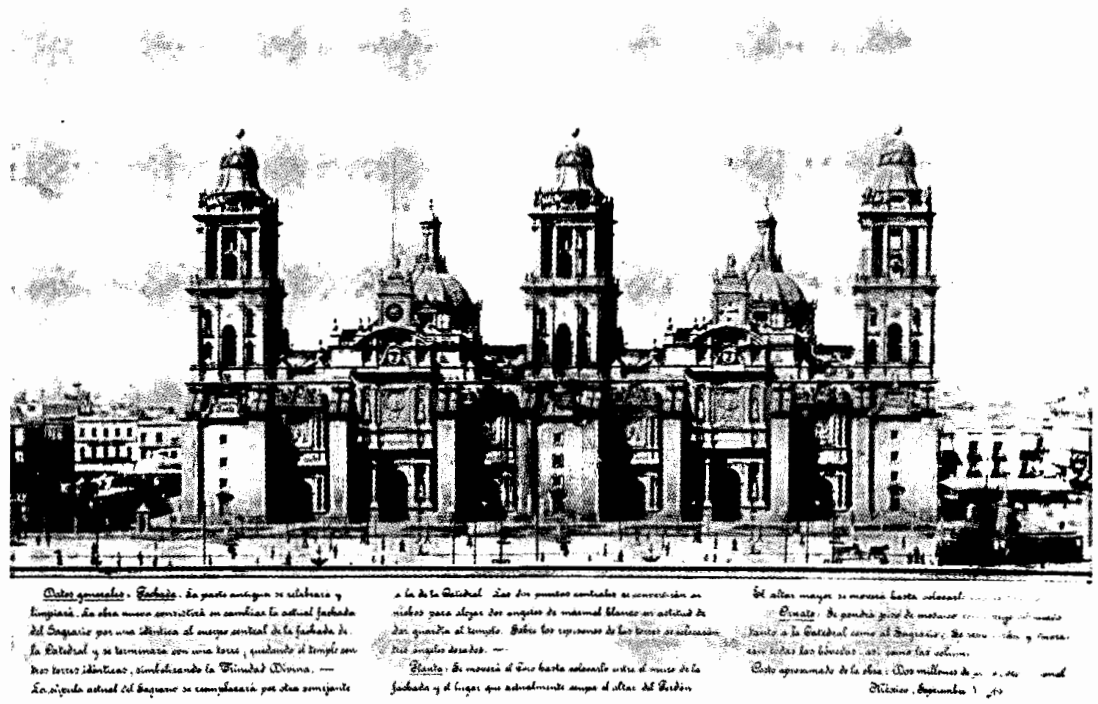


Coyuntura: politica, ideas

La crisis económica de los años treinta llevó a un profundo debate sobre las políticas del Estado que marcó un cambio de rumbo de los tradicionales patrones políticos. La Gran Depresión diluyó el poder político que los republicanos habían tenido sobre el gobierno desde finales del siglo XIX. Al inicio del New Deal, los empresarios y los nuevos demócratas en el poder reconocieron la necesidad de coordinar la producción y la distribución de los mercados para así poder estabilizar la economía. Nuevas coaliciones políticas aparecieron y nuevas instituciones se formaron para articular los cambios en las políticas de Estado. $^{53}$

Durante los años treinta tuvo lugar un importante realineamiento electoral, que creó las condiciones necesarias para un proceso de cambios políticos. El realineamiento del New Deal trajo consigo un refuerzo del Partido Demócrata. ${ }^{54}$ Uno de los más notables cambios fue el fin de las regiones como las líneas divisorias entre demócratas y republicanos y la aparición de los class issues. Durante el New Deal, los demócratas se hicieron más fuertes en el norte y en el este, y los republicanos incrementaron su poder entre los blancos del sur, esto llevó a un incremento en la competencia interestatal e intrarregional entre los partidos. ${ }^{55}$

Las elecciones de la Cámara de Representantes en 1932 fueron un giro de los resultados tradicionales. Los demócratas obtuvieron entre 7 y $15 \%$ de los votos en

\footnotetext{
${ }^{53}$ Gourevitch, Politics, 1986, pp. 127-148.

${ }^{54}$ Burnham, Critical, 1970.

${ }^{55}$ McSweeney y Zvesper, American, 1991, pp. $29-31$.
}

todos los estados de Nueva Inglaterra. De igual manera, en las elecciones de 1934 y 1936 , los demócratas obtuvieron una copiosa votación en el noroeste y en los estados centrales de noreste. El resultado final fue que el noroeste de Estados Unidos, antes un fuerte bastión del republicanismo, se movía hacia un sistema electoral bipartidista competitivo. ${ }^{56}$ Este cambio radical del mapa electoral llevó a los demócratas al dominio de la Cámara de Representantes desde 1932 hasta 1946. De 1932 a 1938, los demócratas lograron controlar tanto el norte urbano e industrializado como el sur agrícola. ${ }^{57}$ Lo anterior creó un ambiente receptivo, esencial para los cambios en la estrategia económica del gobierno de Roosevelt.

Los elementos ideológicos también desempeñaron un papel fundamental en la creación del NIRA. El conflicto entre la expansión de las capacidades administrativas y la tradicional ideología antiestatista había sido siempre un obstáculo en el desarrollo del aparato del Estado estadunidense.

Los primeros años del New Deal fueron un periodo particular en la historia de Estados Unidos en tanto que la crisis económica eclipsó momentáneamente la preocupación estadunidense sobre el poder gubernamental y se logró una relativa tregua entre las visiones sobre la necesidad de expandir las capacidades del Estado y de la tradición liberal. ${ }^{58} \mathrm{El}$ cambio en las mentalidades o, por lo menos, el reconocimiento de la necesidad de incrementar el poder público, herencia de la Progressive Era, permitió a Roosevelt expandir

${ }^{56}$ Brady, Critical, 1988, pp. 94-97.

${ }^{57}$ Ibid., p. 101.

${ }^{58}$ Morone, Democratic, 1990; Brady, Critical, 1.988, p. 129. 
las capacidades administrativas del Estado. La competencia por los mercados había sido remplazada por la cooperación y por la planeación nacional mediante la creación de oficinas federales no sólo como la NRA sino también como la Agriculture Adjustment Agency (mayo de 1933), la Civil Works Administration (noviembre de 1933), la Fram Credit Administration (junio de 1933), y la Civilian Conservation Corporation (marzo de 1933), entre otras. ${ }^{59} \mathrm{La}$ crisis económica había creado un espacio fértil para la recuperación de las ideas progresistas sobre la planeación, el desarrollo del aparato administrativo y la política social que tuvieron lugar a principios del siglo xx. La explosión de políticas de bienestar social durante el New Deal también fue resultado de una larga historia de propuestas de innovación administrativa hacia políticas de bienestar que habían sido hechas a un lado una y otra vez.

Durante la era progresista de inicios de 1900, intelectuales, clases medias y políticos se cuestionaron seriamente las bondades del laissez-faire, prevaleciente desde finales del siglo XIX, y propugnaban por mejores y mayores medidas del Estado para limitar el poder y la codicia de los grandes capitalistas. La Interstate Commerce Commission y el Sherman Antitrust Act fueron las únicas medidas de regulación federal sobre los intereses de los empresarios durante el siglo XIX. ${ }^{60} \mathrm{Se}$ puede decir que el país se dividía en dos líneas ideológicas en cuanto a los mecanismos de intervención estatal en la economía. Por un lado se encontraban los Nuevos Libertarios, bajo el liderazgo de

\footnotetext{
${ }^{59}$ Couch y Shughart II, Political, 1998, p. 21.

${ }^{60}$ Hawley, New, 1.989, p. 6.
}

Woodrow Wilson. Dentro de este grupo se encontraban personajes como Louis Brandeis. Los Nuevos Libertarios consideraban la necesidad de limitar los privilegios de las grandes empresas mediante el férreo control de los monopolios, la liberalización del crédito de Wall Street y la eliminación de prácticas desleales de comercio. Por su parte los Nuevos Nacionalistas, liderados por Theodore Roosevelt, consideraban que la concentración del poder era inevitable, que generaba mayor riqueza como también innovación tecnológica. El Estado debía entonces participar en la planeación económica y en la regulación. El mecanismo de control era la "democratización" de los grandes imperios. ${ }^{61}$

Poco antes de la primera guerra mundial y durante la guerra, los Progresistas pusieron gran atención a las experiencias sociales europeas, en particular, el desarrollo de las políticas sociales de Alemania, Francia y Gran Bretaña. Pensadores como H. G. Wells, Walter Lippman, Harold Laski y J. A. Habson, entre muchos que participaban en el recién nacido semanario progresista The New Republic, evaluaban el desarrollo de las políticas sobre empleo, vivienda y salarios que se desarrollaban en Europa. Las conexiones personales y familiares al otro lado del Atlántico de una nueva nación americana formada de inmigrantes era un factor clave para el estudio y para la construcción de puentes de conocimiento de lo que sucedía con el desarrollo capitalista y el socialismo en el viejo continente. ${ }^{62}$ Durante la primera guerra mundial el interés en Europa no cayó, al contrario, existió una renovada disposición por comprender los mecanis-

\footnotetext{
${ }^{61}$ Ibid., pp. 7-10.

${ }^{62}$ Rodgers, Atlantic, 1998.
} 
mos de planeación y organización social e industrial durante el esfuerzo bélico. El colectivismo de los tiempos de guerra experimentado por los países europeos alentó el pensamiento progresista en Estados Unidos y el desarrollo de las estructuras básicas del gobierno estadunidense para enfrentar la primera guerra mundial. La planeación nacional y el autogobierno en la industria se movieron al frente de la agenda de desarrollo industrial durante la primera guerra. Estructuras administrativas como la WIB, The Shipping Board y la Emergency Food and Fuel Administration fueron el resultado del más claro sentido de la cooperación apoyado por el sector empresarial por medio de las cámaras de comercio empresariales y hombres como el financiero Bernard Baruch. ${ }^{63}$

Después de la guerra, los progresistas pretendieron institucionalizar muchas de las estructuras del esfuerzo colectivista de la guerra; pero el impulso antiburocráctico se impuso una vez más y, con él, el desmantelamiento de muchas de estas estructuras. Si bien Herbert Hoover trajo consigo la experiencia de cooperación de la guerra al centro del proyecto del Partido Republicano en 1920, lo era más bien en el sentido de una asociación entre gobierno, empresarios (mediante las cámaras de comercio) y trabajadores, y no precisamente de intervención del Estado en la economía. ${ }^{64}$

Durante la Gran Depresión, los nuevos demócratas de los años treinta revivieron la doctrina progresista sobre el fortalecimiento del aparato administrativo; sin embargo la renovada doctrina se enfrentaba a los antitrusters o neobrandesia-

${ }^{63}$ Ibid., pp. 280-284.

${ }^{64}$ Ibid., p. 306. nos, quienes apoyaban únicamente la legislación antimonopolio para así favorecer una política de descentralización de la estructura empresarial y una conducta competitiva. ${ }^{65}$ Para este grupo, la Gran Depresión no era más que el producto de las rigideces económicas creadas por los monopolios. ${ }^{66}$ Por su parte, los planeadores económicos del gobierno de Roosevelt consideraban que las acciones en contra de los monopolios eran anacrónicas y no resolvían ningún problema. Consideraban que en una economía moderna la concentración del poder era inevitable y necesaria una producción en masa y un desarrollo tecnológico más eficiente. Para ellos la respuesta real estaba en la racionalización, en la organización sistemática y en la planeación. ${ }^{67}$

Un factor primordial en el desarrollo de la planeación nacional en el gobierno de Roosevelt y esencial en el desarrollo del NIRA fue la participación de un importante grupo de académicos provenientes en su mayoría de la Universidad de Columbia (Nueva York), conocido como el Brain Trust, como asesores del presidente Roosevelt a partir de la primavera de $1932 .{ }^{68}$

El Brain Trust estaba compuesto esencialmente por Raymond Moley, Rexford Tugwell y Adolf Berle Jr; Moley, politólogo, había sido director de la Cleveland Foundation, una fundación privada que apoyaba el diseño de políticas para enfrentar problemas urbanos mediante herramientas académicas. Moley desarrolló la Moley's Cleveland Crime Survey que

${ }^{65}$ Couch y Shughart II, Political, 1998, pp. $12-$ 13, y Leuchtenburg, Franklin, 1963, pp. 56-57.

${ }^{66}$ Hawley, New, 1966, p. 12.

${ }^{67}$ Ibid., p. 13.

${ }^{68}$ Badger, New, 1989, p. 62. 
lo llevó a dirigir un centro de investigación sobre crimen y justicia en la Universidad de Columbia. Tugwell, economista, dedicado a la economía aplicada y un duro crítico de la "mano invisible", proponía la necesidad de controlar los desequilibrios causados por el cambio tecnológico, la capacidad de producción y los ingresos de los consumidores. Para Tugwell, la planeación era el mecanismo para eliminar estos males. Por su parte Berle, abogado graduado de Harvard, era un firme creyente en los lineamientos de la nueva jurisprudencia que consideraba que la ley no podía estar separada de la economía, que debía de ser un mecanismo de ingeniería social. Para Berle, el problema del gobierno era cómo ejercer un firme control sobre la concentración de poder del capital y cómo hacer a los administradores responsables de sus acciones. Desde 1927, Berle era profesor de la escuela de leyes de la Universidad de Columbia.

El Brain Trust fue decisivo en la visión que el presidente Roosevelt tenía sobre los problemas nacionales. Una de las características de este grupo fue su interés por las ideas que circulaban en Europa en torno a la planeación y a la cartelización de las economías. La idea de utilizar las capacidades de planeación del Estado para construir un proceso de concertación entre los intereses reunidos en la economía tendería a generar un desarrollo mucho más estable que la competencia por los mercados, ésta era la visión central que de la economía tenían Moley, Tugwell y Berle. ${ }^{69}$ El grupo consideraba que la crisis no era un factor externo a la economía estadunidense que podía resolverse median-

${ }^{69}$ Rodgers, Atlantic, 1998, p. 421. te la generación de confianza entre los empresarios, como lo había creído y afirmado el presidente Hoover. Al contrario, existían problemas estructurales en la economía estadunidense como la mala distribución del ingreso, la baja capacidad de compra de los consumidores, la caída en los ingresos de los granjeros estadunidenses, así como los bajos salarios de los trabajadores industriales que explicaban la caída en el consumo. La respuesta estaba, pues, en el desarrollo de mecanismos de planeación industrial que racionalizaran las políticas de precios, de producción, de salarios, junto con la creación de políticas de bienestar. ${ }^{70}$

Finalmente, un factor a considerar como espacio ideológico favorable al desarrollo de las capacidades del Estado fue la crítica del "formalismo legal" por los pragmáticos entre los jueces y los abogados durante la Progressive Era y el New Deal, y en los cuales podemos encontrar a Adolf Berle $\mathrm{Jr} .^{71} \mathrm{La}$ crítica al formalismo legal era similar a la tradicional discusión filosófica entre racionalistas y relativistas. En contra de la universalidad de reglas y de principio, los pragmáticos argumentaban que ningún "sistema abstracto podía anticipar cualquier caso posible y dar una solución determinante". ${ }^{72}$ Los pragmáticos consideraban que no existía una conexión lógica entre los principios generales y los casos individuales por lo que la ley podía ser utilizada como un instrumento de política pública y debía ser aplicada caso por caso. Este argumento se adaptaba magníficamente a la lógica del derecho consuetudinario y al

\footnotetext{
${ }^{70}$ Badger, New, 1989 , pp. 64-65.

${ }^{71}$ Brand, Corporatism, 1988, p. 38.

${ }^{72}$ Ibid., p. 39.
} 
progresismo de la época, además de que tenía mucho sentido durante la expansión del Estado administrativo en tiempos del progresismo y del New Deal. ${ }^{73}$

Esto no significó que el pensamiento hegemónico entre abogados y jueces fuese uno de tipo colectivista o a favor de la planeación e intervención del Estado en la economía. Durante el New Deal la Suprema Corte de Justicia estaba fuertemente influida por jueces como Oliver Wendell Holmes y Louis D. Brandeis quienes habían construido una escuela de pensamiento en torno al control de los intereses monopólicos, a favor de un sistema económico conformado por un mundo de pequeñas empresas con independencia económica y un gobierno cuyas acciones no fueran más allá que simplemente restaurar y preservar la libre competencia. ${ }^{74}$ No sólo dentro de la Suprema Corte y en el Senado existía un grupo antitruster, también dentro de la misma administración de Roosevelt existía un grupo importante de funcionarios públicos de alto nivel temerosos de la concentración del poder económico, entre ellos se encontraba Robert $\mathrm{H}$. Jackson, director de la Antitrust Division; William O. Douglas de la escuela de leyes de la Universidad de Yale que se convirtió en el director de la Securities and Exchange Comision; el secretario del Interior Harold

${ }^{73}$ Ibid., p. 39.

${ }^{74}$ Cabe hacer notar que en los tiempos del New Deal, siete de los nueve miembros de la Suprema Corte de Justicia (Charles Hughes, Willis van Devanter, George Sutherland, Harlan Stone, Owen Roberts, Benjamin Cardozo y Pierce Butler) habían sido nombrados por presidentes republicanos. En línea internet $<$ http://www.spartacus.schoolnet.co.uk/USAsupreme. htm>.
Ickes; así como el profesor de leyes de la Universidad de John Hopkins, Herman Oliphat, quien se convirtió en general counsel del Departamento del Tesoro. ${ }^{75}$

\section{DEBILIDAD DEL ESTADO Y CAÍDA DEL NIRA}

El National Industrial Recovery Act se llevó a cabo gracias a una agencia del gobierno federal llamada la National Recovery Administration, encabezada por el general Hugh Johnson y un equipo de funcionarios públicos con experiencia en la WIB bajo el símbolo del águila azul. ${ }^{76} \mathrm{La}$ NRA era una agencia independiente que sólo rendía cuentas ante el ejecutivo y que tenía el poder de desarrollar códigos de competencia justa en cada sector industrial y de hacerlos cumplir. La tarea de esta agencia era inmensa, por lo que tuvo más de 3000 empleados y creó más de 500 códigos que afectaban $96 \%$ de la industria estadunidense. ${ }^{77}$

La Recovery Administration no pudo cumplir con el programa de recuperación industrial mediante la cooperación de empresarios y de trabajadores debido a dos factores: el limitado poder del Estado y el subdesarrollo de sus capacidades administrativas. De forma especial, la NRA se enfrentó a dos problemas desde el momento de su creación, mismas que pusieron en entredicho su existencia: primero, la falta de una tradición burocrática y un

${ }^{75}$ Hawley, New, 1966, pp. 284-287.

${ }^{76}$ El general Hugh Johnson había ayudado a organizar el servicio militar obligatorio durante la primera guerra mundial y había sido el enlace entre el ejército y la WiB. Véase ibid., pp. 64-65.

${ }^{77}$ Skocpol y Finegold, "State", 1982, pp. 264-265. 
sistema de información confiable sobre los bienes y'servicios producidos por el sector productivo del país; y en segundo lugar, la incapacidad del Estado de imponer su voluntad.

Ya que la NRA comenzó prácticamente de cero, se enfrentó a la carencia de un grupo de personal calificado. Debido al lento desarrollo del aparato administrativo, las agencias gubernamentales carecían de cuadros de burócratas entrenados. Contrariamente, las grandes empresas y las cámaras de comercio (trade associations) tenían grupos de funcionarios altamente calificados que se habían desarrollado desde finales del siglo XIX. A esta organización no le quedó otra alternativa que reclutar a la mayoría de sus altos mandos de la filas de la burocracia empresarial. ${ }^{78}$ Los tecnócratas o businesscrats de la NRA eran, por lo tanto, simpatizantes de las visiones empresariales sobre la industria. ${ }^{79}$

El segundo problema de la NRA era la falta de información acerca de las industrias. Para poder crear los códigos industriales, ésta dependía de la información que las asociaciones empresariales tenían sobre sus miembros. La razón por la cual las asociaciones de comercio tenían un buen sistema de información está relacionada con el proceso de cabildeo que las asociaciones desarrollaron desde mediados del siglo XIX para modificar las preferencias de los políticos y para defender los intereses de sus miembros. ${ }^{80}$ Debido a la limitada autonomía del conocimiento técnico acerca de la industria, la carencia

${ }^{78}$ Ibid., p. 265.

${ }^{79}$ Galambos, Competition, 1966, p. 206. La palabra businesscrats la tomamos de Galambos.

${ }^{80}$ Ibid., p. 10. de habilidades organizacionales y por el hecho de que los miembros de la Junta Asesora (la Industrial Advisory Board), así como los funcionarios más importantes de la NRA fueran businesscrats, el poder de la agencia estaba sometido a los intereses de los grupos empresariales. Esto no significa que los oficiales del gobierno no tuvieran algún control sobre las decisiones de esta organización ni que la participación del movimiento obrero no fuera importante en la creación e implantación de los códigos, sólo hay que analizar la sección 7(a) del NIRA. Sin embargo, la autonomía de la NRA estaba severamente limitada.

El poder del Estado y el liderazgo eran también un problema dentro de la Recovery Administration. La administración de Roosevelt tuvo que negociar con los grupos empresariales más importantes del país los códigos de industria, en particular los códigos laborales. El mismo presidente tuvo que negociar y presionar a importantes hombres de negocios como los presidentes del Consejo de la United States Steel Company y Bethlehem Steel, para que éstos aceptaran los códigos de industria presentados por el gobierno. A pesar de negociar con un gran número de empresas, compañías muy importantes en las ramas de la industria automotriz y minera se negaron a aceptar los códigos de la NRA. Los contratos colectivos de trabajo eran considerados una seria amenaza a estas industrias debido al uso extensivo que hacían de la mano de obra. Por ejemplo, la Recovery Administration fue incapaz de presionar a Henry Ford a negociar y tuvo que organizar el sector sin la presencia de la Ford Motor Company. ${ }^{81}$ La

${ }^{81}$ Schlesinger, Coming, 1959, p. 117. 
Recovery Administration fue también poco eficaz en forzar a los pequeños negocios a obedecer los códigos de industria que protegían la negociación colectiva, salarios mínimos, controles en la producción y en los precios. Era mucho más complicado poder hacer un monitoreo del cumplimiento de los códigos entre las empresas pequeñas que en industrias altamente concentradas como la acerera, la eléctrica, la manufacturera, la del cobre, la del papel y la del vidrio. ${ }^{82} \mathrm{El}$ uso de la coerción como instrumento para aplicar la ley tenía límites, pues desde sus inicios la Recovery Administration fue una oficina del gobierno que operaba fuera de los canales tradicionales del gobierno federal y había llevado a su máximo los poderes constitucionales del ejecutivo, de allí que su legitimidad y constitucionalidad siempre fueron cuestionadas. ${ }^{83}$

Aunado a todo esto la NRA fue también incapaz de resolver las constantes disputas con los empresarios sobre la codificación de las regulaciones relativo a precios, producción y asuntos laborales. Había conflictos entre los intereses de los grandes empresarios, las cámaras de comercio, los distribuidores, los negocios independientes y los trabajadores. ${ }^{84}$ Para poder manejar el gran número de conflictos entre los trabajadores y las empresas se creó la National Labor Board como parte de la NRA en agosto de $1933 .^{85}$

82 Hawley, New, 1989, p. 118.

${ }^{83}$ Brand, Corporatism, 1988 , p. 155.

${ }^{84}$ Skocpol, "Political", 1980, p. 178; Skocpol y Finegold, "State", 1982, p. 267.

${ }^{85}$ Schlesinger, Coming, 1959, p. 147.
EL. PODER DE LOS EMPRESARIOS Y EL NIRA

Desde finales del siglo XIX, el capital industrial en Estados Unidos se encontraba bien organizado. Para 1933 existían compañías con un formidable poder económico y administrativo, asociaciones de comercio que representaban una gran variedad de pequeñas empresas y un importante número de cámaras de comercio como la Cámara de Comercio y la Asociación Nacional de Industriales, con gran capacidad de movilización. ${ }^{86}$

En los inicios de la década de los años treinta, gran parte de la comunidad empresarial estadunidense consideraba que una de las principales causas de la Gran Depresión había sido la terrible competencia por los mercados. ${ }^{87}$ Importantes empresarios compartían con el gobierno la visión de que la recuperación industrial se lograría mediante la cooperación y la planeación. Un grupo significativo de empresarios argumentó que la única manera de iniciar un proceso de recuperación industrial era reviviendo la política industrial de Hoover y las leyes antimonopolio. Asociaciones de comercio como el Cotton Textile Institute, una asociación encargada de formular políticas, conformó un movimiento de asociaciones a principios de los años treinta que junto con la Cámara de Comercio llamó a un cambio en las políticas públicas que fomentaban la competencia. ${ }^{88}$ Las asociaciones de comercio, generalmente, habían hecho un

${ }^{86}$ Leuchtenburg, Franklin, 1963, p. 10.

87 Véase Morone, Democratic, 1990, p. 154; Schlesinger, Coming, 1959, pp. 93-95, y Gourevitch, Politics, 1986, p. 149.

${ }^{88}$ Galambos, Competition, 1966, p. 200. 
fuerte cabildeo a favor de una revisión profunda del Sherman Antitrust Act. Las políticas antimonopolio afectaban seriamente la capacidad de racionalizar y mitigar una fiera competencia en algunos sectores del mercado. ${ }^{89}$

De igual forma, las grandes compañías estaban preocupadas por la difícil situación económica y la necesidad de estabilizar los mercados. Hombres de negocios como Gerard Swope, presidente de la General Electric Company y quien conocía bien la WIB, afirmaba sobre la necesidad de la recuperación industrial mediante la organización de las grandes empresas bajo los auspicios del gobierno federal. ${ }^{90} \mathrm{La}$ propuesta de Swope llamaba a la suspensión de las leyes antimonopolio para que las empresas pudieran participar en la planeación económica por medio de las asociaciones de comercio, las cuales estabilizarían los mercados mediante controles a la producción y a los precios. La opinión de Swope no era compartida en su totalidad por todos los grandes empresarios del país, empresarios como Alfred P. Sloan de General Motors, James A. Farrell de U. S. Steel, entre otros, estaban de acuerdo con Swope en cuanto a la necesidad de relajar las leyes antimonopolio, pero estaban en total desacuerdo con que los empresarios fueran organizados por el gobierno. ${ }^{91}$ Sin embargo, la profundización de la crisis económica en 1932 hizo que muchos de los industriales aceptaran la idea de la intervención gubernamental en la economía.

Durante las elecciones presidenciales de 1932, el Partido Republicano y su can-

\footnotetext{
89 Brand, Corporatism, 1988, p. 151.

${ }^{90}$ McQuaid, Big, 1982, p. 22.

${ }^{91}$ Ibid., p. 24.
}

didato Herbert Hoover fueron renuentes a dar concesiones que generaran algún tipo de proceso de cartelización. Los miembros de la comunidad empresarial, en un giro desesperado, dieron su apoyo político a Roosevelt, quien sostenía la necesidad de flexibilizar las leyes antimonopolio. ${ }^{92}$ Con la victoria de éste, las organizaciones empresariales adquirieron un papel importante en el diseño e implantación de la política industrial en los primeros años del New Deal.

Las organizaciones de comercio desempeñaron un papel central en el diseño de los códigos industriales de la NRA. Como lo he planteado con anterioridad, el comité de reglas de esta organización estaba básicamente integrado por organizaciones empresariales. Los dirigentes más importantes de la Recovery Administration provenían de la burocracia empresarial y gran parte de la información sobre los sectores industriales era proporcionada a la NRA por las asociaciones de comercio. Los pequeños empresarios consideraban que el gobierno podía, mediante las organizaciones empresariales, limitar el freeriding y controlar a aquellos que no respetaban los acuerdos relativos al control de precios y lograr así la estabilización del mercado. ${ }^{93}$

La suspensión de las leyes antimonopolio como resultado del NIRA parecía una clara victoria de algunos intereses industriales que apoyaban la cartelización. Sin embargo, ante el temor de la concentración del poder económico, el NIRA se vio forzado a construir una serie de compromisos políticos que limitaron el poder de los empresarios. Contrario a los intereses

\footnotetext{
${ }^{92}$ Ibid., p. 25.

${ }^{93}$ Brand, Corporatism, 1988, pp. 152-153.
} 
del capital, éste estableció que la Recovery Administration y el ejecutivo tenían el poder de determinar la imparcialidad de los códigos industriales y el poder de hacerlos cumplir. El NIRA también garantizó al movimiento obrero el establecimiento de un salario mínimo, límites al día y semana laboral, prohibiciôn del trabajo infantil $y$, muy importante, la sección 7(a) de esta ley establecía el derecho de los trabajadores a negociar de forma colectiva sus contratos laborales, así como crear su propios sindicatos. Si bien estos compromisos políticos con el sector laboral significaban un serio revés a los intereses de los hombres de negocios, la ambigüedad del pacto con el movimiento obrero, la inquietud por la recuperación industrial, la relajación de las políticas antimonopolio y la posibilidad de la estabilización de los mercados, así como la creciente influencia de los empresarios en la administración Roosevelt eran razones suficientes para que los dueños del capital continuaran apoyando el NIRA.

Después de que esta ley fue promulgada, los grandes capitalistas trataron de influir en el gobierno del presidente Roosevelt. Hombres de negocios como Gerard Swope, Walter Teagle de la Standard Oil Company of New Jersey, y Louis Kirstein del Federal Department Stores colaboraron con los miembros del gabinete del presidente para crear el Business Council. El propósito de este organismo era el de cooperar con el gobierno en el diseño de una estrategia de recuperación industrial. El Consejo reunió aproximadamente a 60 presidentes de las mayores corporaciones industriales del país. ${ }^{94}$ El Business Council, controlado por grandes capitalistas, y

${ }^{94}$ McQuaid, Big, 1982, p. 30. el Industrial Advisory Board, controlado por las asociaciones de comercio, eran piezas importantísimas en el proceso de formulación de los códigos industriales de la Recovery Administration. El objetivo fundamental del Business Council y del Industrial Advisory Board era presentar una serie de códigos de competencia y, al mismo tiempo, mediar los desacuerdos entre las industrias. ${ }^{95}$

\section{El poder empresarial y el fin del NIRA}

Antes de que la Suprema Corte de Justicia consignara la sentencia sobre la inconstitucionalidad del NIRA y de la Recovery Administration, los grandes y pequeños empresarios habían comenzado a confrontar el Recovery Act, afirmando que no era una medida factible para la recuperación industrial. Existían dos elementos principales que disuadieron a la comunidad empresarial para dejar de apoyar políticamente el arreglo de cooperación entre empresarios, trabajadores y gobierno. Primero, el incremento en la organización sindical como consecuencia de la sección 7(a) del NIRA. En segundo lugar, el incremento sustancial en los conflictos entre empresas y la incapacidad de la Recovery Administration de promover la recuperación económica.

El desencanto de los grandes y pequeños empresarios con esta ley comenzó poco después de que la Recovery Administration fue establecida. Para el verano de 1933 , tres meses después de que entrara en vigor el NIRA, una ola de huelgas impactó empresas importantes de los sectores de la industria automotriz, del ace-

95 Ibid., p. 33. 
ro y del hule. Durante los primeros meses de 1933, los días laborales perdidos no excedían los 603000 , pero en julio se perdieron 1375000 y 2378000 en agosto. ${ }^{96}$

El resultado de la sección 7(a) del NRA fue la organización de los trabajadores. Sin embargo, la respuesta de los empresarios fue de confrontación, cierres patronales, despidos y el control de los trabajadores por medio de sindicatos organizados por los mismos patrones. Los conflictos entre el capital y el trabajo eran tan intensos que el programa de recuperación industrial se encontraba seriamente amenazado por el número y significancia de las huelgas en el país. Para resolver los problemas, el Business Council y la Industrial Advisory Board de la NRA propusieron una tregua con el movimiento obrero para poder lograr un compromiso nacional y resolver la difícil problemática de las huelgas y el impulso organizacional. ${ }^{97}$ Los empresarios accedieron a apoyar el salario mínimo, topes a las jornadas de trabajo diaria y semanal, la prohibición del trabajo infantil, así como el derecho de los trabajadores de negociar colectivamente y crear sus propios sindicatos. La American Federation of Labor (AFL) aceptó por su parte dar fin a las huelgas, pero rechazó controlar el impulso hacia la organización de los trabajadores.

Para poder encontrar un mecanismo que resolviera las dificultades ente el capital y el trabajo, un grupo de cuatro personajes integrado por Gerard Swope, Walter Teagle, John Frey (AFL) y William Green (presidente de la AFL) aceptaron que la Junta Nacional de Arbitraje (Na-

${ }^{96}$ Morone, Democratic, 1990, p. 168.

${ }^{97}$ Ibid., p. 34. tional Labor Relations Board) fuera creada y encabezada por el senador Robert Wagner, demócrata de Nueva York. Roosevelt nombró al senador Wagner para encabezar la National Labor Relations Board (NLB).$^{98}$ Esta junta estaba constituida por tres representantes de la industria y tres representantes de los trabajadores organizados, además de Wagner como presidente. El objetivo de la NLB era asegurar la sección 7(a) de la ley constitutiva del NIRA y arbitrar en los conflictos entre los trabajadores y los patrones. ${ }^{99}$

La NLB era un cuerpo administrativo sin un mandato claro, procedimientos poco definidos y sin un poder real para hacer cumplir sus recomendaciones. Para poder imponer sus decisiones, ésta tenía que apoyarse en las acciones de la NRA o del Departamento de Justicia. Como árbitro de las relaciones trabajo-capital la junta se volvió una verdadera pesadilla para los empresarios. Esta junta era capaz de intervenir en el lugar de trabajo y auspiciar elecciones para asegurarse de que los trabajadores esraban genuinamente representados por sindicatos de su agrado y que éstos eran elegidos por un sistema de mayoría. ${ }^{100}$ Así pues, la NLB acabó estable-

${ }^{98}$ Ibid., pp. 35-37.

${ }^{9}$ Véase Fleming, "Significance", 1957, pp. 123155.

${ }^{100}$ De hecho, la NLB se enfrentaba a un asunto complejo, pues los trabajadores y los empleadores se enfrascaron en una discusión básica sobre la representación, entre la regla de mayoría y la regla de representación proporcional. Los empleadores consideraban que los trabajadores deberían ser representados por el sindicato de su preferencia, lo que significaba un mecanismo sencillo para romper con las organizaciones sindicales, véase Morone, Democratic, 1990 , p. 169. 
ciendo un nuevo grupo de engorrosas obligaciones para las empresas. ${ }^{101}$

En el invierno de 1933-1934, la frustración de los empresarios estaba en su máximo y amenazaba con explotar. Una ola de huelgas estalló; un estimado de 1500000 trabajadores se fueron a la huelga y ocurrieron cientos de paros. ${ }^{102}$ Las huelgas fueron el resultado de la renuencia de los empresarios de hacer efectivos los compromisos laborales establecidos. Los pequeños y medianos empresarios agrupados en la National Association of Manufacturers eran particularmente reacios a reconocer cualquier tipo de negociación colectiva, así como a sindicatos no organizados por la compañía. ${ }^{103}$ Estas pequeñas compañías que utilizaban mano de obra intensiva consideraban que sus ganancias se reducían al punto de la bancarrota como consecuencia de las demandas laborales y los códigos de la NRA sobre control de precios y de producción. Pero, por el otro lado, algunas grandes corporaciones estaban más preocupadas por la estabilización de la economía que por confrontar los procesos de sindicalización y de negociación colectiva.

Sin embargo, entre las corporaciones más grandes del país había un importante grupo de empresarios conservadores como Pierre Du Pont y Alfred Sloan, que se oponían furiosamente a la negociación colectiva y a la representación por mayoría dentro de los sindicatos. Du Pont y Sloan presionaron a los empresarios para que dejaran de apoyar a la NRA y a la política económica de Roosevelt. ${ }^{104} \mathrm{Hacia}$ el final

\footnotetext{
${ }^{101}$ Schlesinger, Coming, 1959, p. 148.

${ }^{102}$ Levine, Class, 1988, p. 183.

${ }^{103}$ McQuaid, Big, 1982, p. 42.

${ }^{104}$ Ibid., p. 51.
}

de 1934, y después de un año de disputas laborales, cooperar con la Recovery Administration difícilmente se había convertido en un factor funcional para pequeños o grandes empresarios. El NIRA, la NRA y la NLB habían fomentado la organización obrera y habían politizado los conflictos obrero-patronales.

Un segundo elemento importante en la caída del NIRA fue el fracaso de la Recovery Administration, y de los empresarios mismos, para resolver las disputas entre las industrias y echar a andar la esperada recuperación. La perspectiva de encontrar estándares nacionales de industria sin enfrentar entre sí a las industrias era una labor extremadamente difícil debido a la diversidad de intereses de los empresarios. ${ }^{105}$ Esto fue reconocido por importantes líderes empresariales. ${ }^{106}$ Por un lado, la NRA quería representar los intereses de la industria para así construir estándares nacionales, pero, por otro lado, tenía que aceptar los distintos intereses de las diferentes fracciones del empresariado. La creación de los códigos que controlaban tanto precios como producción era un punto de conflicto importante entre los dueños de capital. Era sabido que los códigos industriales brindarían la recuperación de algunas empresas a costa de otras. ${ }^{107}$ Un ejemplo de las tensiones

105 Sobre la fragmentación de los empresarios véase Martin, Shifting, 1991, p. 35.

${ }^{106}$ McQuaid, Big, 1982, p. 50.

107 Existe un debate entre historiadores sobre si el diseño de estos códigos estuvo controlado por los intereses del capital monopolista, así como también si los controles de precios y producción estaban diseñados para permitir a las empresas más importantes destruir la competencia de las más pequeñas. Véase Brand, Corporatism, 1988, y Levine, Class, 1988. 
entre los empresarios es el caso de compañías como Johnson \& Johnson Company y el Cotton Textile Institute (CTI). Johnson \& Johnson enfrentó los códigos de la NRA en cuanto a restricciones sobre la relación hombre-máquina, argumentando a favor de la eficiencia por arriba de la estabilización. El cTi refutó los argumentos de Johnson \& Johnson bajo el principio de que las firmas más pequeñas se verían lesionadas por la competencia abierta. El debate terminó cuando los funcionarios de la NRA rechazaron la postura de Johnson \& Johnson y le exigieron aceptar los códigos de controles a la producción. ${ }^{108}$ Es claro que el proceso de diseño de los códigos había abierto la arena política a los conflictos entre empresarios, lo que no era funcional para el desarrollo de los negocios en tanto que demandaba tiempo, organización y recursos, además de que extendía los conflictos entre empresas a la arena pública.

Finalmente, el descontento de los pequeños empresarios hacia el New Deal y la NRA se vio acelerado por el problema de créditos para las pequeñas compañías. Una dificultad mayor para las pequeñas empresas durante la Gran Depresión fue la falta de créditos. La administración Roosevelt falló en su intento por atender dicho problema. En consecuencia, los pequeños negocios percibieron que sus ganancias se reducían como resultado de los altos costos relacionados con las provisiones laborales, los controles de precios, los controles a la producción y las dificultades al acceso de crédito. ${ }^{109}$

${ }^{108}$ Galambos, Competition, 1966, pp. 253-255.

${ }^{109}$ Brand, Corporatism, 1988, pp. 153-154.

\section{LOS TRABAJADORES Y EL NIRA}

A lo largo de su historia el movimiento obrero en Estados Unidos ha sido desorganizado y políticamente débil. La vida del movimiento obrero estadunidense ha sido de constante lucha por el reconocimiento de los derechos de los trabajadores. Durante el New Deal muchos de los derechos por los cuales los obreros de Estados Unidos habían luchado por décadas, por fin, fueron reconocidos.

El movimiento obrero moderno en este país comenzó su desarrollo a finales del siglo XIX. Los dos factores fundamentales que determinaron su impulso fueron: primero, la creación de una masa crítica de trabajadores, la cual se convirtió en la pieza central del nuevo sindicalismo, y el incremento substancial de obreros calificados como resultado de la ola de inmigraciones europeas. En segundo lugar, el impacto de la crisis económica de 1880 en los hogares de los trabajadores. Fue durante este periodo que la American Federation of Labor (AFL) nació. ${ }^{110}$

Sin embargo, la aparición del movimiento obrero sólo tuvo un impacto marginal en la política estadunidense. En la última década del siglo XIX, las decisiones políticas importantes de Estados Unidos estuvieron controladas por las corporaciones empresariales más grandes del país con el sustento de los partidos políticos $y$ las cortes. A finales del siglo XIX y principios del $\mathrm{xx}$ aparecieron serios conflictos entre trabajadores y patrones. La mayoría de estos conflictos fue el resultado de la continua negación de los empresarios a reconocer a los sindicatos y la negocia-

\footnotetext{
1. Lo Galenson, "Historical", 1986.
} 
ción colectiva. ${ }^{111}$ La continua oferta de mano de obra barata, provista por las constantes migraciones de trabajadores europeos a Estados Unidos, acentuaba la lucha de las corporaciones en contra del sindicalismo. ${ }^{112}$

Mediante la AFL, los obreros en las empresas manufactureras se opusieron a los intentos de los empresarios de abrir el contrato a trabajadores no sindicalizados. En estas décadas, las cortes le dieron al Estado estadunidense el sustento de una ideología empresarial. Para el Estado, dominado por las cortes y por los partidos políticos, el interés público se entendía sólo como la protección de los derechos de propiedad y de la promoción del desarrollo económico. La corporación estaba concebida como un agente del interés público y se consideraba que el empresario capitalista cumplía una importante necesidad pública. La devoción de las cortes hacia el capitalismo era proporcional a la antipatía que tenía la cultura del sistema legal de Estados Unidos hacia las organizaciones de trabajadores. Los sindicatos eran acusados de intervenir en los derechos de propiedad. Más aún, el sistema legal hizo nulo cualquier intento de los sindicatos de convertirse en los legítimos interlocutores de los trabajadores. ${ }^{113} \mathrm{La}$ Suprema Corte de Justicia de Estados Unidos utilizaba al Sherman Antitrust Act como un mecanismo para evitar la sindicalización, hasta que el Clayton Act de 1914 determinó que no existía ningún elemento en el Sherman Act que impidiera la organización de los trabajadores. El Clayton Act no eliminó la posibilidad

111 Tomlins, State, 1985, pp. 11-12.

112 Galenson, "Historical", 1986, pp. 43-44.

${ }^{11.3}$ Piore y Sable, Second, 1984, pp. 23-30. de que las cortes federales utilizaran su poder para intervenir en las disputas laborales, hasta que el Norris-La Guardia Act de 1932 removió tal poder. ${ }^{114}$

El aumento en la organización sindical y la actividad huelguística hacia 1900 fue también el resultado del intento de las corporaciones, en particular de las compañías ferrocarrileras, de controlar la organización de la producción y el trabajo mediante la reorganización de los procesos productivos. Esta era una consecuencia directa de la introducción de nuevas tecnologías y de innovaciones organizacionales. ${ }^{115}$ El rechazo de las corporaciones a la sindicalización estuvo motivado porque los sindicatos representaban una amenaza al control de la administración sobre la empresa. ${ }^{16} \mathrm{El}$ conflicto industrial continuó a todo lo largo de la progressive era. El impacto de la producción en masa sobre la organización del movimiento obrero no cambió la temática de los conflictos capital-trabajo: el control sobre los procesos de producción y organización del trabajo. ${ }^{117}$

\footnotetext{
${ }_{114}$ Derber y Young, Labor, 1957, p. 125.

11.5 Piore y Sable, Second, 1984, p. 16.

${ }^{116}$ Ibid., p. 64.

117 En el periodo anterior a la primera guerra
} mundial hubo un importance aumento de la influencia socialista en el movimiento obrero estadunidense, en particular entre los sindicatos industriales. Este fenómeno fue resultado del disgusto de los trabajadores sobre la posición voluntarista de la AFL hacia el Estado. Esto era resultado de la preferencia de ésta hacia los sindicatos de oficios. Contrariamente a la AFl, organizaciones socialistas como la Industrial Workers of the World (IWw), constituida en 1905 por trabajadores semicalificados y no calificados, favorecía acciones de huelga directa como la huelga en lugar de cualquier tipo de negociación colectiva. Sin embargo, la vida de las organizaciones de izquiceda 
El rechazo del sistema legal estadunidense a la sindicalización llevó a un continuo conflicto entre la AFL y el poder judicial desde finales del siglo XIX hasta principios del xx. Las cortes argumentaron que los sindicatos como asociaciones voluntarias no tenían una personalidad legal, por lo tanto, éstos no podían demandar a los empleadores por romper con el contrato establecido. ${ }^{118}$ Sin embargo, para 1908 las críticas de esta organización se dirigieron más hacia el Partido Republicano que a las cortes. Los líderes de la AFL argumentaron que el control republicano de los poderes ejecutivo y legislativo bloqueaba la legislación que podía beneficiar al sector obrero.

Por otra parte, la falta de una estrategia para influir dentro del ámbito gubernamental por parte de la AFL era resultado de experiencias pasadas. Los sindicatos estadunidenses habían descubierto que era difícil movilizar hacia sus intereses a las instituciones y reglas del régimen. De esta manera, la AFL había escogido luchar por su interés en la esfera privada más que en la esfera pública. ${ }^{119}$

Con la crisis de 1929, la presión por lograr la negociación colectiva y los derechos de los trabajadores hizo erupción. La mitad de las industrias cerradas y 13000000 de desempleados. La falta de una política dirigida al sector obrero modificó el apoyo del sector obrero del Great Old Party (GOP) al Partido Demócrata. El voto de la clase trabajadora fue un ele-

fue corta como resultado de la violencia y represión utilizadas en su contra por empresas y gobierno. Véase Laslett, "Socialism", 1974, pp. 123-125, y Galenson, "Historical", 1986, p. 96.

${ }^{118}$ Galenson, "Historical", 1986, p. 83.

119 Morone, Democratic, 1990, p. 152. mento fundamental en la victoria del presidente Roosevelt y el control demócrata sobre el Congreso. ${ }^{120}$

A pesar de las presiones del sector obrero hacia la nueva administración demócrata, la movilización obrera no era una amenaza a la estabilidad política del país, debida a la poca fuerza política del movimiento obrero. Por lo mismo, los programas de estabilización industrial creados por el poder legislativo para proteger al sector obrero fueron más bien resultado de iniciativas amistosas del Congreso, del apoyo del gobierno federal o del Partido Demócrata, que resultado de la capacidad de movilización del sector obrero. ${ }^{21}$ Aún más, las iniciativas para el bienestar de la clase obrera estadunidense eran parte de una política general de recuperación económica. La normatividad sobre salarios mínimos y jornadas de trabajo era parte de un plan económico para resolver el problema del desempleo y reactivar el consumo. Las políticas de apoyo al sector laboral durante el New Deal fueron en gran medida el resultado de las presiones del electorado en áreas urbano-industriales. Durante las elecciones de 1932, y a lo largo del New Deal, representantes demócratas y senadores se dieron cuenta de la importancia de la legislación a favor de los obreros para así consolidar sus mayorías electorales. ${ }^{122}$

Cuando el NIRA fue promulgado, el movimiento obrero organizado estuvo complacido con la inclusión de disposiciones laborales y la presencia del sector en los comités para el diseño de los códigos industriales de la NRA. Sin embargo,

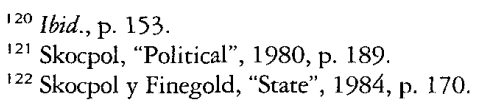


los representantes del sector significaron menos de $10 \%$ de los que inicialmente las autoridades habían establecido. ${ }^{123}$

El principal objetivo de la Recovery Administration era la cooperación de los empresarios y trabajadores al programa de recuperación industrial. Por lo mismo, esta organización, junto con los empresarios, estaba muy interesada en repetir la experiencia con los trabajadores de la $\mathrm{Na}$ tional War Labor Board. ${ }^{124}$

Uno de los elementos más importantes para obtener la completa participación de los empresarios en las medidas del NIRA fue la paz laboral. Sin embargo, de manera paradójica, fue éste el principal mecanismo que estimuló los conflictos industriales de 1932 a 1935. Durante esos años, tales conflictos fueron el resultado del diseño de los códigos industriales, la aplicación de las normas laborales y los derechos de los trabajadores a la negociación colectiva. Estos dos elementos alimentaron los conflictos entre los empresarios y estimularon la organización de la clase trabajadora.

Para 1933, la economía del país comenzó a experimentar un incremento en el nivel de la organización de los trabajadores y las disputas administrativo-laborales. Tanto artesanos como obreros industriales se organizaron. Los sindicatos industriales lucharon por su organización fuera de la AFL, la cual estaba dominada por los intereses de los sindicatos de oficios. ${ }^{125}$ De hecho, el liderazgo de esta organización no tenía ningún control sobre los trabajadores industriales y los no capacitados. Los empleados se convirtieron en el motor

1.23 Skocpol y Finegold, "State", 1982, p. 265.

${ }^{124}$ McQuaid, Big, 1982, pp. 37-38.

1.25 Ibid., p. 33. de la organización obrera en industrias tan importantes como la del acero, la automotriz, la textil, la química y la del hule. ${ }^{126}$

Como resultado de los conflictos entre el capital y el trabajo, y el temor de la movilización política, la comunidad empresarial de Estados Unidos trató de restaurar la estabilidad industrial. El Business Council y el Industrial Advisory Board se reunieron con los miembros del Comité Asesor Laboral de la Recovery Administration. Como resultado de estas reuniones y para arbitrar los conflictos entre trabajadores y empresa se creó la National Labor Board (NLB). ${ }^{127}$ Sin embargo, la creación de ésta no puso fin al rechazo empresarial a la implantación de las normas laborales y el derecho de sindicalizarse. El desencanto de la clase trabajadora con la Recovery Administration provocó la continuación de los conflictos industriales durante todo 1935.

\section{Movimiento obrero y fin del NIRA}

A pesar de la debilidad histórica del movimiento obrero en Estados Unidos, el desarrollo de sus acciones fue un componente fundamental en el colapso del NIRA. Para obtener la cooperación del sector privado en las medidas de recuperación, uno de los objetivos más importantes de la Recovery Administration era la de pacificar y controlar el movimiento obrero. Sin embargo, el efecto inmediato de la política laboral del NIRA fue la erupción de la organización obrera, la fortaleza del movimiento obrero y, en consecuencia, el conflicto industrial.

$$
\begin{aligned}
& { }^{126} \text { Ibid., pp. 41-42. } \\
& { }^{127} \text { Ibid., pp. 34-35. }
\end{aligned}
$$


Los enfrentamientos obrero-patronales durante la vida del NIRA fueron resultado de dos factores. Primero, el tradicional rechazo de los empresarios estadunidenses a aceptar la negociación colectiva. Sin embargo, con la introducción de las políticas laborales durante la Recovery Administration, la comunidad de los negocios se vio frente a una situación distinta. A pesar de la debilidad estructural de la Recovery Administration y de la NLB para presionar a las empresas para que cumplieran con las provisiones laborales, las organizaciones obreras y las negociaciones colectivas emergieron como consecuencia directa de la política pro trabajadores del NIRA. En consecuencia, el incremento de las disputas entre trabajadores y empresarios fue el resultado del rechazo de las prerrogativas laborales y de la organización obrera. En segundo lugar, la debilidad representacional de la AFL en los sindicatos industriales tuvo como resultado su incapacidad por controlar los sindicatos industriales y los conflictos obreropatronales. Cabe añadir que la Labor Advisory Board de la NRA estaba fundamentalmente constituida por líderes de la AFL, lo que reducía la capacidad de la Recovery Administration de controlar e incluir a los sindicatos industriales. La incapacidad de la AFL de representar y de controlar a los grandes sindicatos industriales de Estados Unidos sólo se modificó cuando hacia finales de la década de los treinta la AFL logró unir su fuerza con el Congress of Industrial Organizations (CIO) y dar nacimiento a la confederación obrera más importante de la nación estadunidense, la AFL-CIO.

Como podemos ver, la relación entre el movimiento obrero, el NIRA y su enfrentamiento a los intereses de los empre- sarios sólo fue un factor más en la muy compleja relación entre el presidente Roosevelt, la Recovery Administration y el sistema político establecido. La decisión tomada por la Suprema Corte de Justicia de Estados Unidos la tarde del 27 de mayo de 1935 sobre la inconstitucionalidad del National Industrial Recovery Act fue el veredicto que anunciaba la muerte y el fin de un difícil intento de negociación tripartita y, tal vez, del programa más ambicioso de política pública de la primera mitad del siglo Xx en los Estados Unidos de América.

\section{CONCLUSIONES}

La historia del NIRA en la vida política de Estados Unidos ejemplifica dos aspectos importantes en el análisis de las instituciones políticas a lo largo del tiempo. Por un lado, que las crisis aparecen como "coyunturas críticas" que brindan una ventana de oportunidades a los actores políticos para generar nuevos arreglos institucionales. Pero que, por otro lado, los intentos por construir nuevos arreglos siempre se enfrentan a las instituciones e intereses establecidos. En Estados Unidos la tentativa de Roosevelt por construir un mecanismo de negociación tripartita se enfrentó con un sistema de reglas que había generado un régimen político que se caracterizaba por la debilidad del Estado administrativo, el poder del capital, la diversidad de intereses empresariales, y la incapacidad de movilización y organización de los trabajadores.

Para los latinoamericanos y en particular para los mexicanos cabe añadir que un dato curioso que nos deja la reflexión acerca de Roosevelt y del NIRA es la gran cer- 
canía y distancia con la historia política mexicana de los años treinta y el desarrollo del corporativismo mexicano como mecanismo para organizar la política y la economía mexicana. El intento de Roosevelt encontró su fracaso ante la incapacidad administrativa del Estado, el poder de las cortes, la fuerza del desarrollo empresarial y la debilidad del movimiento obrero. Al contrario, el gobierno de Lázaro Cárdenas logró la construcción del corporativismo mexicano gracias a la alianza que construyeron los gobiernos revolucionarios con los trabajadores, la debilidad del empresariado después del proceso revolucionario, el control del ejecutivo sobre el poder judicial y el legislativo, la historia de un partido único y la inexistencia de una democracia competitiva. La vida del NIRA también nos hace reflexionar sobre la distancia que existe entre Estados Unidos y México, "vecinos distantes"; pero también los puntos de encuentro entre estas dos naciones cuyos nacionalismos nos han hecho creer su "excepcionalidad" ante la falta de un análisis serio acerca de la historia de sus instituciones políticas. El objetivo de este trabajo es el de comprender la importancia del desarrollo histórico de las instituciones estadunidenses en la explicación de las estrategias políticas y sus resultados como políticas públicas en la vida política de Estados Unidos durante la primera parte del New Deal. ${ }^{128}$ Particularmente, la manera como la crisis de 1929 y su profundización produjo una realineación de las coaliciones políticas tradicionales y con ella una avalancha de nuevas y diferentes instituciones que se enfrentaron a las limitantes definidas por las instituciones y los intereses estableci-

${ }^{128}$ Collier y Collier, Shaping, 1991, pp. 27-39. dos. A lo largo de este trabajo se cuestiona un supuesto generalmente dado, la singular e innata incompatibilidad entre los arreglos corporativistas y la tradición liberal en la política estadunidense, para demostrar que la lucha entre lo colectivo y lo individual ha sido un elemento importante a lo largo del desarrollo político de Estados Unidos.

\section{BiBLIOGRAFÍA}

-Badger, Anthony J., The New Deal. The Depression Years, 1933-1940, The Noonday Press, Nueva York, 1989.

-Brady, David W., Critical Elections and Congressional Policy Making, Stanford University Press, Stanford, California, 1988.

-Brand, Donald, Corporatism and the Rule of Law, Cornell University Press, Ithaca, Nueva York, 1988.

-Burnham, Walter Dean, Critical Elections and the Mainspring of American Politics, W. W. Northon and Company Inc., Nueva York, 1970.

-Conkin, Paul K., The New Deal, AHM Publishing Corp., Arlington Height, Illinois, 1.975. -Collier, Ruth Berins y David Collier, Shaping the Political Arena, Princeton University Press, Princeton, Nueva Jersey, 1991.

-Couch, Jim F. y William F. Shughart II, The Political Economy of the New Deal, Edward Elgar, Northampton, Massachusetts, 1998.

-Derber, Milton y Edwin Young (comps.), Labor and the New Deal, The University of Wisconsin Press, Madison, 1957.

-Ferguson, Thomas, "Industrial Conflict and the Coming of the New Deal: The Triumph of Multinational Liberalism in America" en Steve Fraser y Gary Gerstle (comps.), The Rise and Fall of the New Deal Order, 1930-1980, Princeton University Press, Princeton, Nueva Jersey, 1989, pp. 3-31. 
-Fleming, R. W., "The Significance of the Wagner Act" en Milton Derber y Edwin Young (comps.), Labor and the New Deal, The University of Winsconsin Press, Madison, 1957, pp. 123-155.

-Galambos, Louis, Competition and Cooperation, The John Hopkins Press, Baltimore, 1966.

-Galenson, Walter, "The Historical Role of American Trade Unionism" en Seymour Martin Lipset (comp.), Unions in Transition: Entering the Second Century, Institute for Contemporary Studies, San Francisco, 1986.

-Gourevitch, Peter, Politic in Hard Times, Cornell University Press, Ithaca, Nueva York, 1986.

-Gunther, Gerald, Constitutional Law, The Foundation Press, Inc., Mineola, Nueva York, 1985.

-Hartz, Louis, The Liberal Tradition in America, Harcourt Brace Jovanovich Publishers, Nueva York, 1955.

-Hawley, Ellis W., The New Deal and the Problem of Monopoly. A Estudy in Economic Ambivalen$c e$, Princeton University Press, Princeton, 1966.

-, "The New Deal State and the Antibureaucratic Tradition" en Robert Eden (comp.), The New Deal and its Legacy, Greenwood Press, Westport, Connecticut, 1989.

-Laslett, John H. M., "Socialism and American Trade Unionism" en John H. M. Laslett y Seymour Martin Lipset (coords.), Failure of a Dream?, University of California Press, Los Ángeles, California, 1974.

-Leuchtenburg, William E., Franklin D. Roosevelt and the New Deal, 1932-1940, Harper and Row Publishers, Nueva York, 1963.

-Levine, Rhonda F., Class Struggle and the New Deal, University of Kansas Press, Lawrence, Kansas, 1988.

-Martin, Cathie Jo, Shifting the Burden, University of Chicago Press, Chicago, 1991.

-McQuaid, Kim, Big Business and Presidential Power, William Morrow and Company, Nueva York, 1982.
-McSweeney, Dean y John Zvesper, American Political Parties, Routledge, Londres, 1991.

-Morison, Samuel Eliot, The Oxford History of American People, Oxford University Press, Nueva York, 1965.

-Morone, Jim A., The Democratic Wish, Basic Books, Nueva York, 1990.

-National Recovery Administration, $A$ Handbook of NRA: Laws, Regulations, Codes, Federal Codes Inc., Washington, D. C., 1933.

-Piore, Michael J. y Charles F. Sable, The Second Industrial Divide, Basic Books, Nueva York, 1984.

-Przeworski, Adam, "The Neoliberal Fallacy", Journal of Democracy, John Hopkins University Press, núm. 3, julio de 1992, Washington, D. C., pp. 45-59.

-Rodgers, Daniel T., Atlantic Crossings. Social Politics in a Progressive Age, The Belknap Press of Harvard University Press, Cambridge, Massachusetts, 1998.

-Schlesinger, Arthur M. Jr., The Coming of the New Deal, Houghton Miffling Company, Cambridge, Massachusetts, 1959.

-Skocpol, Theda y Kenneth Finegold, "State capacity and economic intervention in the early New Deal', Political Science Quarterly, Academy of Political Science, núm. 2, verano de 1982, Nueva York, pp. 255-278.

__ " "State, Party and Industry: from Business Recovery to the Wagner Act in America's New Deal' en Charles Bright y Susan Harding (comps.), Statemaking and Social Movements, The University of Michigan Press, Ann Arbor, Michigan, 1984.

-Skocpol, Theda, "Political Responses to Capitalist Crisis: Neo-marxist Theories of the State and the Case of the New Deal', Politics and Society, SAGE, vol. 10, núm. 2, 1980, Thousand Oaks, California, pp. 55-201.

-Skowronek, Stephen, Building a New American State, Cambridge University Press, Cambridge, 1982. 


\section{SECUENCIA}

-Tomlins, Christopher, The State and the Unions, Cambridge University Press, Cambridge, 1985.
-Zinn, Howard (comp.), New Deal Thought, Bobbs-Merrill, Nueva York, 1966.
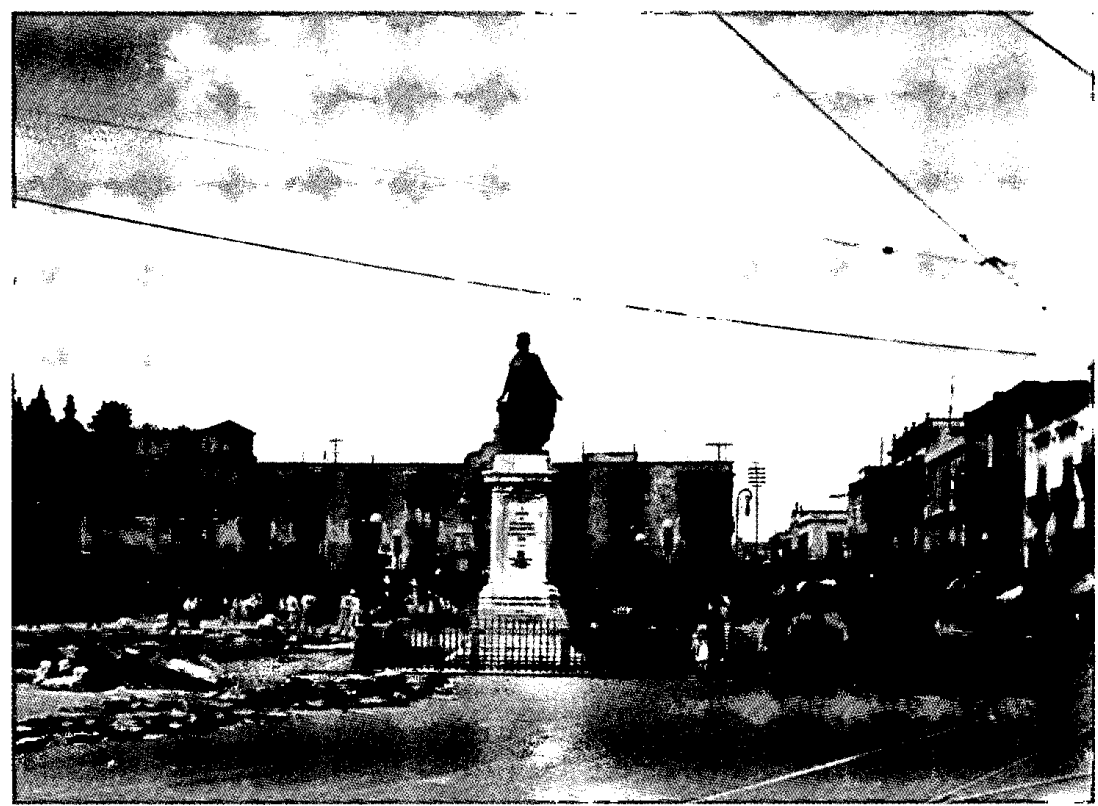


\section{SECUENCIA}

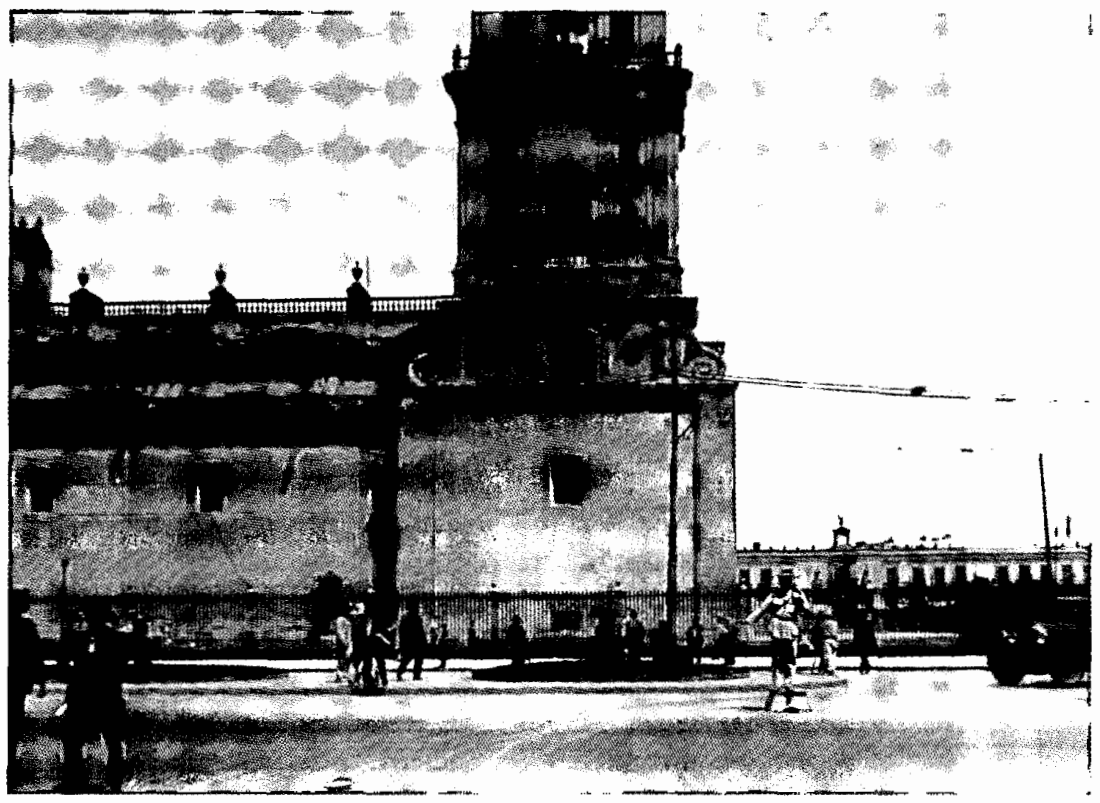




\section{SECUENCIA}

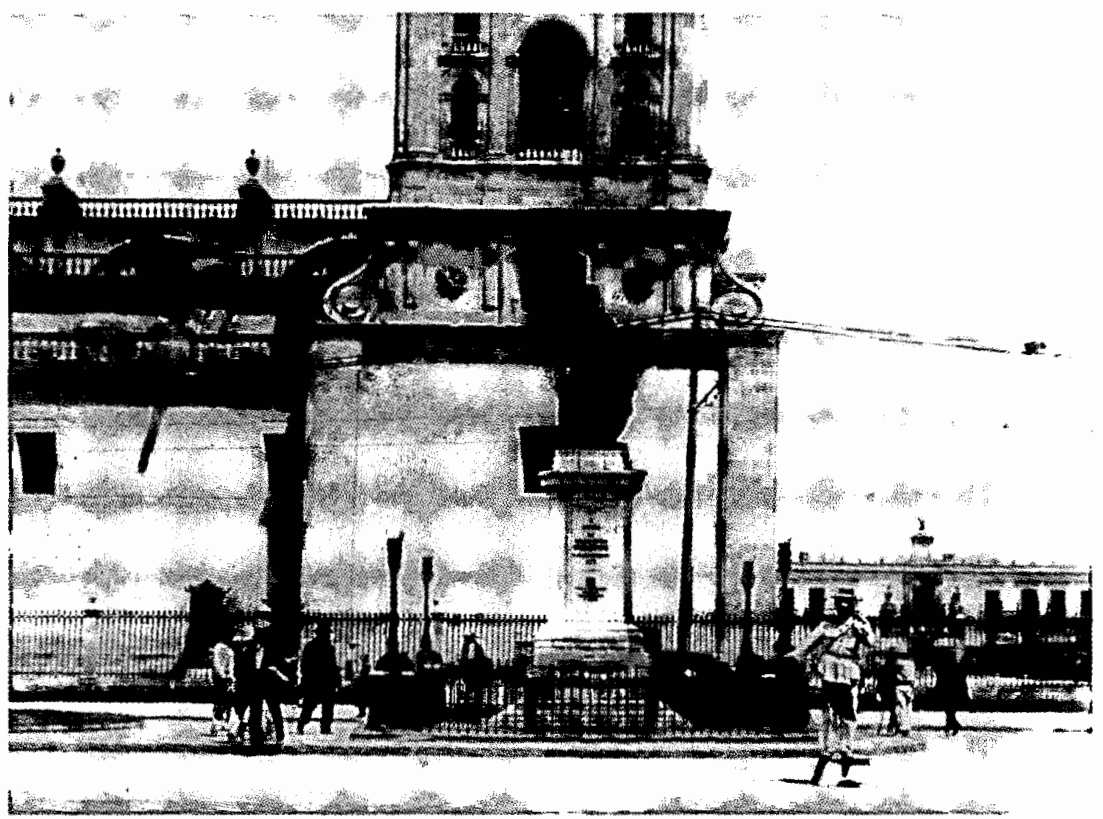

